\title{
O MUNDO DE OZ DE L. FRANK BAUM: CONTO DE FADAS MODERNIZADO, UTOPIA NORTE-AMERICANA OU ALTA FANTASIA AVANT LA LETTRE?
}

Bruno Anselmi Matangrano ${ }^{1 \star}$ São Paulo, SP, Brasil

\begin{abstract}
Resumo
$\mathrm{Na}$ introdução de O Maravilhoso Mágico de Oz (1900), L. Frank Baum declara sua intenção de inaugurar um novo tipo de conto de fadas, ao mesmo tempo mais moderno e mais americano. O resultado de seu projeto se traduz pela criação de um universo complexo, que se expande ao longo de treze sequências e obras derivadas, alcançando imenso sucesso midiático. Desde então, muito se especula sobre o gênero ou modo narrativo ao qual a série de $\mathrm{Oz}$ se enquadra, pois, embora Baum a aponte como um conto de fadas, e, portanto, associada ao maravilhoso, logo sua obra foi lida como uma utopia norte-americana e como uma precursora da fantasia. A partir desse contexto e de tais questionamentos, o presente estudo propõe uma leitura do universo criado por Baum buscando elementos dessas três categorias para compreender seu lugar no cânone da fantasia, ao mesmo tempo em que procura entender a importância do uso de mapas na construção de mundos secundários, elemento que ao longo do século XX se popularizou em obras dessa vertente ${ }^{1}$.

Palavras-chave: Maravilhoso; Utopia; Fantasia; L. Frank Baum; Oz
\end{abstract}

\section{THE WORLD OF OZ, BY L. FRANK BAUM: MODERNISED FAIRYTALE, NORTH AMERICAN UTOPIA, OR HIGH FANTASY AVANT LA LETTRE?}

\begin{abstract}
In the introduction to The Wonderful Wizard of Oz (1900), L. Frank Baum asserts his intention of bringing forth a new type of fairy-tale, at once more modern and more American. Such goal translates into the creation of a complex universe that gets expanded by means of thirteen
\end{abstract}

\footnotetext{
${ }^{*}$ Bacharel, mestre e doutor em Letras pela Universidade de São Paulo (USP), concentrando suas pesquisas sobre as literaturas simbolista e decadentista, assim como sobre as vertentes do insólito ficcional. É membro dos grupos de pesquisa POEM (Poéticas e Escritas da Modernidade), da USP, e "Nós do Insólito: vertentes da ficção, da teoria e da crítica”, da Universidade Estadual do Rio de Janeiro (UERJ), assim como do LÉA (Lire en Europe Aujourd'hui), rede de pesquisa internacional da Universidade de Lisboa (FLUL). Já publicou vários artigos, traduções e contos em revistas, jornais e obras coletivas e é autor dos livros Contos para uma noite fria (2014) e Fantástico Brasileiro: o insólito literário do romantismo ao fantasismo (2018), com Enéias Tavares. Seu e-mail é: bamatangrano@yahoo.com.br. ORCID: https://orcid.org/0000-0001-7914-0804
} 
sequels and derivative works, and knows a huge mediatic success. Ever since its first publication, it has been debated - and still is - in which genre the $\mathrm{Oz}$ series fits, as, even though Baum describes it as a fairy-tale, therefore related to the marvellous, it was read as a North American utopia and a forerunner of fantasy. In this context, keeping these questions in mind, this paper discusses Baum's universe by searching elements from these three categories, so that we may understand its place in the fantasy canon, simultaneously seeking to understand the usage of maps at building secondary worlds, a quite popular feature in fantasy works during the 20th century.

Key-words: Marvellous; Utopia; Fantasy; L. Frank Baum; Oz. 


\section{O universo de Baum, seu sucesso e expansão transmidiática}

No ano de 1900, o escritor norte-americano L. Frank Baum (1856-1919) publicou aquela que viria a ser sua mais célebre história, dentre os mais de sessenta livros que escreveu: O Maravilhoso Mágico de Oz, talvez hoje mais conhecido - ou antes injustamente ofuscado - por suas muitas adaptações para outras mídias e pelos produtos dele derivados, notadamente, pelo filme O Mágico de Oz, de 1939, dirigido por Victor Fleming (1889-1949), também responsável pelo premiado E o vento levou, do mesmo ano.

Ilustrada por W. W. Denslow (1856-1915), a história de Oz conheceu o sucesso imediato, sendo um dos livros infantis mais vendidos nos EUA nos dois anos subsequentes ao seu lançamento. Baum logo passou a receber centenas de cartas de jovens leitores pedindo mais histórias passadas naquele universo e dois anos depois, em 1903, o livro chegava aos palcos em adaptação homônima, que, ao contrário da obra original, tinha como público-alvo os adultos, sendo a primeira de sete histórias passadas naquele universo levadas ao teatro pelas mãos do próprio Baum.

Diante de tamanho reconhecimento, pouco após sua aparição, não surpreende que o livro tenha rapidamente recebido não uma, mas treze continuações - além de uma série de contos reunida em dois volumes, Queer Visitors from the Marvelous Land of $\mathrm{Oz}$ (1905) e Little Wizard Stories of Oz (1913), um spin-off intitulado The Woogle-Bug Book (1905), além de mais de dez outras histórias, entre contos e romances, relacionadas ao complexo e bem desenvolvido universo da série, como American Fairy Tales (1901), Dot and Tot of Merryland (1901), The life and adventures of Saint Claus (1902), The Queen Zixi of Ix (1905) e Sky Island (1912) - todos publicados entre 1900 e $1920^{3}$ e constantemente adaptados para outras mídias, dentre as quais, o cinema, a televisão, o teatro e a história em quadrinhos. Além disso, o mundo criado por Baum inspirou diversas continuações escritas por diferentes autores, como Ruth Plumly Thompson (1891-1976), John R. Neill (1877-1943) - responsável pelas ilustrações da série de Baum a partir do segundo volume -, e Jack Snow (19071956), também autor de um importante guia de personagens da série, intitulado Who's Who in $\mathrm{Oz}(1954)^{4}$.

$\mathrm{Oz}$ permanece vivo, por assim dizer, na contemporaneidade, graças às frequentes releituras, tais como The Unknown Witches of Oz: Locasta and the Three Adepts, de Dave Hardenbrook, publicado no ano 2000, por ocasião do centenário do primeiro volume da saga original, a célebre série literária The Wicked Years (1995-2011), de Gregory Maguire, que deu origem ao famoso musical da Broadway, e Dorothy must die (2014-2017), de Danielle Page, para só citar as mais famosas, sem mencionar também as revisitações audiovisuais, como o filme Oz, Mágico e Poderoso (2013), dirigido por Sam Raimi e produzido pelos estúdios Disney, e a bem recente e malsucedida série televisiva Emerald City (2017), criada por Matthew Arnold e Josh Friedman e produzida pelo canal NBC, cancelada após a baixa audiência da primeira temporada. Esse constante 
movimento de recriação ajudou a fixar as personagens e lugares criados por Baum em nosso imaginário.

Tamanho sucesso $^{5}$ se deve, não apenas às personagens cativantes, ao nacionalismo intrínseco do enredo, às belas e provocativas ilustrações de Denslow, mas, sobretudo, à originalidade do primeiro livro da série - e de suas continuações - na construção de seu mundo, motivo pelo qual a classificação modal e/ou genérica ainda gera constantes discussões. Os livros de $\mathrm{Oz}$ ora são classificados como contos de fadas modernos, conforme proposto pelo próprio autor, ora como utopias representativas dos ideais norte-americanos (viés adotado pela crítica contemporânea a Baum), ora, ainda, como precursores da fantasia, como se pretende demonstrar neste artigo, vertente adotada por grande parte da crítica especializada atualmente.

\section{Entre a tradição e a inovação, uma obra de difícil classificação}

Em sua "Introdução" a O Maravilhoso Mágico de $\mathrm{Oz}^{6}$, primeiro volume da série, Baum (2014b) declarou ter a intenção de inaugurar um novo tipo de conto de fadas, propondo uma história para crianças que fosse, ao mesmo tempo, mais moderna - em oposição aos contos de fadas do dinamarquês Hans Christopher Andersen (1805-1875) e àqueles reunidos pelos irmãos alemães Jacob (17851863) e William Grimm (1786-1859) - e também mais alinhada aos valores e ideais norte-americanos, como se vê no trecho abaixo:

Folclore, lendas, mitos e contos de fadas acompanharam a infância através das eras, pois todo jovem saudável tem um amor sadio e instintivo por histórias fantásticas ${ }^{7}$, admiráveis e manifestamente irreais. As fadas aladas de Grimm e Andersen trouxeram mais felicidade para os corações infantes do que qualquer outra criação humana.

Mas o conto de fadas dos velhos tempos, tendo servido por gerações, pode agora ser classificado como "histórico" na biblioteca infantil, pois chegou a vez de uma série de novos "contos de maravilhas", em que o gênio, o anão e a fada estereotipados são eliminados, junto a todos os incidentes horríveis e de gelar o sangue, criados por seus autores com o fim de mostrar uma moral assustadora para cada conto. A educação moderna inclui moralidade, de forma que a criança moderna procura apenas entretenimento em seus contos de maravilhas e dispensa alegremente todo incidente desagradável.

Tendo este pensamento em mente, a história O Maravilhoso Mágico de Oz foi escrita somente para agradar as crianças de hoje. Aspira ser um conto de fadas modernizado, em que o maravilhamento e o contentamento são mantidos, e os corações partidos e pesadelos deixados de fora (BAUM, 2014b, p. 9).

Logo, segundo Baum, mesmo esses contos sendo responsáveis por momentos de grande alegria na vida das crianças, em sua opinião, eram violentos demais e muito estereotipados, o que não considerava mais necessário ao mundo moderno, onde não era mais preciso advertir as crianças, por exemplo, dos perigos de se caminhar numa floresta repleta de ursos ou lobos. Para ele, 
naquele momento inicial do século XX, a literatura para "pequenos leitores", como costumava dizer, deveria simplesmente divertir, nunca assustar. É por isso que Baum decide escrever o que chama de "conto de fadas modernizado", em sua própria expressão, sem os "pesadelos" habituais das narrativas mais antigas, o que não é totalmente verdadeiro: a violência continua bastante presente em suas obras, mas nuançada pelo seu humor irônico e pela atmosfera de absurdo, em alguma medida recuperada da tradição que visa evitar. Cabe, porém, atentar, que apesar do desejo de distanciamento, Baum conserva muito da tradição dos contos maravilhosos, como se vê no trecho abaixo, a partir de uma reflexão sobre alguns dos objetos mágicos presentes no primeiro volume da série:

Não obstante, por mais que Baum tente inovar na criação de um novo tipo de conto de fadas, vários são os elementos que são retomados das histórias tradicionais, por exemplo, os sapatos mágicos de Dorothy que a levam ao Kansas com apenas três passos em muito se parecem com as chamadas "botas de léguas" ou de milhas, tão frequentes em Grimm e Perrault e o próprio chapéu mágico pode ser uma variante de outros tantos chapéus encantados de Grimm ou mesmo da lâmpada maravilhosa de Aladdin, cujo gênio também é escravo de um feitiço que o obriga a realizar três desejos (MATANGRANO, 2014, p. 200).

Nesse mesmo sentido, o estudioso Michael Patrick Hearn (2000), responsável pela edição comemorativa do centenário de publicação de O Maravilhoso Mágico de $\mathrm{Oz}$, não apenas questiona a ideia de Baum de um conto de fadas "modernizado" e mais norte-americano, por sua proximidade ainda muito grande com a tradição europeia, como também aponta o aspecto "utópico" de sua série. Visto antes como indício da originalidade dos livros de Baum, tal aspecto já vinha sendo debatido desde 1929, a partir da publicação de Utopia Americana, de Edward Wagenknecht (1900-2004), considerado o primeiro estudo acadêmico dedicado ao universo oziano, tendo se centrado em eventos narrados no sexto livro da série para defender sua tese, na qual também enfatiza o viés nacionalista da série de $\mathrm{Oz}$, igualmente presente no livro Contos de Fadas Americanos, do próprio Baum, a partir do qual Hearn desenvolve seu argumento:

Não há exagero algum em se enfatizar o quanto o desenvolvimento do conto de fadas "moderno" feito por Baum foi consciente. Houve, é claro, tentativas anteriores de definir a América como uma terra feérica. Contos de Washington Irving e Nathaniel Hawthorne refletem essa busca por uma mitologia americana nativa. No entanto, Baum não se interessava por preservar as lendas locais, como Irving, ou pela metafísica perturbadora de Hawthorne. Baum preocupava-se com os interesses e desejos mais imediatos da criança de sua época. Ao contrário de Hawthorne, escolheu não retornar às tradições greco-romanas para inventar uma mitologia; não sentia necessidade de imitar os contos de fadas dos Grimm, como Pyle fez. Ele explicou, em sua introdução ao livro Baum’s American Fairy Tales, que suas histórias "trazem o selo de nossa época e retratam as fadas progressistas da atualidade". Não olhava para o passado, como seus 
antecessores. Era um progressista, não um romântico. Ansiava e procurava por novas formas. Baum lecionava a crianças, como apontou Edward Wagenknecht em Utopia Americana (Seattle: University of Washington Book Store, 1929), "para buscar o elemento de maravilhamento na vida ao redor delas, para perceber que até mesmo a fumaça e o maquinário poderiam ser transformados em tradição feérica, se ao menos tivéssemos energia e visão suficientes para alcançar as profundezas de sua significância e transformá-los em algo para nosso uso" (p. 29).

Baum não chegou a conseguir criar um conto de fadas puramente "americano". Suas bruxas e magos, sapatos mágicos e chapéus encantados vieram da Europa para povoar o mesmo universo de seus espantalhos, bonecas de pano e panelas mágicas (HEARN, 2000, p. xlix, tradução de Carol Chiovatto ${ }^{8}$ ).

Ultrapassando as classificações genéricas mais imediatas, o resultado desse ousado projeto literário se traduziu pela criação de um universo complexo, composto por vários reinos e raças sencientes recuperados dos contos de fadas tradicionais, mas com "algo a mais", modernizado, portanto, nos termos de Baum. Mas, afinal, em que consiste essa ideia de um "conto modernizado" e em qual medida essa série pode ser considerada como uma utopia norte-americana e como uma precursora da fantasia moderna? Para responder a essa questão é preciso primeiro pensar nas diferenças entre o texto de Baum e os contos maravilhosos tradicionais, bem como nos elementos usados para definir a fantasia e a utopia enquanto gênero literário, ou, antes, enquanto modos narrativos. Primeiramente, porém, convém discutir brevemente o que designa cada uma dessas categorias narrativas.

O conto de fadas é um tipo de narrativa proveniente da tradição oral e pertencente a um modo narrativo mais amplo, conhecido como "maravilhoso", utilizado comumente para definir também outras formas narrativas tradicionais e antigas, como a fábula, o mito, a lenda, a saga etc. Segundo Tzvetan Todorov (1939-2017), nessas histórias "os elementos sobrenaturais não provocam qualquer reação particular nem nas personagens, nem no leitor implícito. Não é uma atitude para com os acontecimentos (TODOROV, 2008, p. 59-60).

Dada sua origem oral, torna-se difícil precisar o surgimento dessa forma narrativa que se confunde em grande parte com as primeiras histórias humanas, como as cosmogonias e outras histórias cujo objetivo é explicar o mundo ou ensinar uma moral, ou lição. As famosas histórias da tradição árabe compiladas sob o título de As Mil e Uma Noites são um ótimo exemplo de contos maravilhosos. Outro exemplo, por sua vez, são justamente os contos de fadas de origem céltica, eslava ou germânica, como os compilados pelos irmãos Grimm. Nos termos de Todorov (2008, p. 60), “o conto de fadas não é senão uma das variedades do maravilhoso e os acontecimentos sobrenaturais aí não provocam qualquer surpresa: nem o sono de cem anos, nem o lobo que fala, nem os dons mágicos das fadas".

Tal definição sumária facilmente pode ser aplicada aos livros da série de $\mathrm{Oz}$, em que de fato encontramos uma intrusão do feérico na realidade, sem, contudo, que haja um conflito. O elemento mágico é prontamente aceito e à medida que esse novo universo é desbravado, uma série de criaturas e objetos extraordinários 
se revela sempre sem causar "qualquer reação particular", conforme prescrito por Todorov (2008).

O conceito de utopia, por sua vez, surge no Renascimento, com a publicação do livro homônimo de Thomas More (1478-1535) em 1516. Seu nome provém do grego através da junção do sufixo "u- "que significa "não" e do radical "tópos", literalmente "lugar". Ou seja, a rigor, a utopia seria o não lugar, um espaço desejado, ainda por ser criado. Em More, esse lugar se apresenta como uma república do dito Novo Mundo, onde os valores seriam diametralmente opostos ao de sua Inglaterra natal: se nesta há preconceito e segregação, naquela há união e respeito; se numa há guerra e violência, na outra, há paz; em suma, se na Inglaterra se prega o individualismo egocêntrico e egoísta, em Utopia, há uma preocupação coletiva com o bem-estar social. Por conta disso, em extensão de sentido, muitas vezes, a utopia passou a designar, portanto, a ideia de eutopia, isto é, um "bom lugar".

Embora seja um conceito renascentista, a ideia de um lugar idealizado a ser descoberto ou construído remonta à Antiguidade, vide a República de Platão, ou mesmo o Éden bíblico. Na Idade Média, a busca por lugares assim motivava as grandes viagens à procura de lugares como a mítica Cocanha, um país onde teoricamente ninguém deveria trabalhar e todos teriam alimento e residência.

A utopia, portanto, mesmo sendo um "não-lugar" em sua etimologia, pressupõe sempre "Outro lugar", o qual a ficção tentará recriar em contraponto aos problemas e desafios presentes no mundo real. Por isso, não raro a narrativa utópica dependerá de uma viagem para acessar esse mundo idealizado, como teoriza Christophe Cavee:

Se a utopia como gênero ou "modo" não se define primeiramente pela sua relação com a viagem, e pareceria mesmo, por natureza, dever excluí-la (enquanto sistema e descrição), é preciso convir todavia que a utopia literária se construiu em grande parte na sua relação com a narrativa de viagem. [...] Antes de se tornar um topos que credibiliza uma ficção, a forma da narrativa de viagens serve para que a utopia narrativa formule a sua relação com o real, ou com o possível. Efetivamente, as grandes descobertas fazem do espaço geográfico o lugar desses "possíveis laterais" com que Raymond Ruyer definia a utopia. A alteridade pode então situar-se num alhures que seria desse mundo, num continuum espaço-temporal - que não exclui, no entanto, os rompimentos necessários à salvaguarda desse alhures... [...] [Por fim, se], na utopia, qualquer viagem supõem um regresso, tal como qualquer utopia supõem uma exterioridade para a dizer e a ver, a viagem de saída da utopia irá tornar-se um sintoma de crítica que trabalha progressivamente contra a utopia: a viagem já não é o topos narrativo necessário à descrição do sistema utópico, mas o fio de uma narração que integra uma "microutopia" (ou várias) antes de a largar, para ultrapassá-la. Reintegrada na narrativa, a utopia, cujo sistema está em conflito com a personagem, mostra os seus limites (CAVEE, 2009, p. 258-259).

Nesse sentido, as utopias se aproximam da alta fantasia por pressupor a existência de outro lugar - ou outro mundo -, cujas regras são diferentes. Em Oz, assim como na Nárnia de C. S. Lewis (1898-1963), a viagem será essencial 
para a descoberta desse novo universo, nos quais se encontram diversas das características associadas à ideia de utopia. Hearn (2000) argumenta que $\mathrm{Oz}$ é "tecnicamente uma Voyage extraordinaire ou uma história de viagem como The Travels of Sir John Mandeville (1375), Robinson Crusoe (1719), de Daniel Defoe, e As Viagens de Gulliver (1726), de Jonathan Swift", e lembra que Mary Devlin "percebe a similaridade entre a Terra de Oz e a Terra de Og, um dos reinos do continente perdido de Lemuria”. O próprio Baum brinca com essa ideia de terras a descobrir, em O Espantalho de Oz (1915), nono livro da série, quando a personagem Ork, comenta: "é assombroso quantos pequenos países existem, escondidos por aí nas fendas e cantos desse grande globo terrestre. Se alguém viajar, pode encontrar algum novo país a cada volta e um bom número deles ainda nem foi colocado nos mapas" (BAUM, 2000, p. 30). Para além dessa relação pela viagem, a relação entre $\mathrm{Oz}$ e as utopias fica mais clara quando relemos o verbete sobre o mundo de Baum no Dicionário de Lugares Imaginários de Alberto Manguel e Gianni Guadalupi:

Em Oz, não há doenças, nem pobreza, nem morte. O dinheiro não existe e tudo pertence à princesa, que trata os súbditos como seus filhos. Cada pessoa recebe tudo o que precisa. A agricultura é muito produtiva e os cereais são suficientes para alimentar toda a população, sendo a colheita distribuída equitativamente. [...] Toda gente trabalha metade do tempo e se diverte na outra metade. As condições de trabalho em $\mathrm{Oz}$ são de molde a que a profissão seja vista como uma fonte de prazer e orgulho, e não como uma imposição.

O país é pacífico e calmo, se bem que possam ser encontrados seres estranhos, e por vezes perigosos, nas florestas densas de algumas zonas (MANGUEL; GUADALUPI, 2014, p. 662).

Ou seja, por esse viés, Oz poderia tanto ser a Cocanha medieval, como a república utópica, de More, embora seja uma monarquia. É uma terra não só utópica em seu sentido primeiro - um não lugar, em relação ao nosso mundo -, mas também uma ucronia, isto é, um "não tempo", uma vez que sem morte ou doenças, a percepção de um tempo contínuo não se aplica. No entanto, nem tudo são flores, afinal, $\mathrm{Oz}$ é um estado absolutista. Carol Chiovatto sintetiza seu sistema de governo, nos seguintes termos:

Não há títulos de nobreza no primeiro livro, além daqueles de governante. Sabemos que o governante da Cidade das Esmeraldas (a capital de Oz) é o Mágico, e que as governantes de cada uma das quatro terras que compõem Oz são bruxas: A Bruxa Boa do Norte, a Bruxa Boa do Sul (Glinda, a Boa), a Bruxa Má do Leste e a Bruxa Má do Oeste. Nesse caso, a autoridade é conferida por um poder real (aquele da bruxaria), tanto para o bem quanto para o mal [...]. A autoridade de Dorothy vem de múltiplos fatores: serviços prestados à comunidade de $\mathrm{Oz}$ (torna-se heroína quando da queda de sua casa sobre a Bruxa Má do Leste); destinadora dos amigos, novamente heroína ao matar a Bruxa Má do Oeste, derretendo-a com água; e destinatária de Glinda (CHIOVATTO, 2015, p. 78). 
Na leitura de Tuerk (2007, p. 191), em alguns momentos Oz flerta com o totalitarismo, com o que ele chama de um "monopólio da magia". No começo de O Maravilhoso Mágico de Oz (BAUM, 2014b), por exemplo, as porções leste e oeste do país são dominadas por duas bruxas tirânicas, o que se aproximaria mais de uma distopia do que de uma eutopia (idem, p. 194). Mesmo após a morte das duas, algumas leis restringem a prática de magia, controlada por Ozma, a governante de todas as províncias, e Glinda, a Bruxa Boa do Sul. "Em Oz, a magia é oficialmente proibida e só pode ser praticada com autorização", comentam Manguel e Guadalupi. "Esta interdição foi imposta, sobretudo, para impedir que as bruxas más do passado readquirissem poder, mas também tem a vantagem de prevenir acidentes" (MANGUEL; GUADALUPI, 2014, p. 664).

A interdição, portanto, não é gratuita, mas demonstra desde já que há leis regendo esse mundo, que há uma hierarquia e que a liberdade pode ser cerceada pelos governantes se assim for considerado melhor para o bem comum. Só que a autoridade de Ozma e Glinda ultrapassa bastante qualquer limite de privacidade, pois possuem recursos mágicos para espionar todos os súditos do reino. Não por acaso, em alguns momentos, como em A Maravilhosa Terra de Oz (BAUM, 2014a), segundo livro da série, o povo se rebela, tentando tomar o poder e subverter algumas regras então vigentes. Logo, como bem salienta Tuerk, a série Oz não pode ser vista como composta apenas por narrativas eutópicas, embora sempre permaneçam utópicas:

Oz é uma utopia ou um não-lugar, mas não é uma eutopia ou um bom lugar. É cheia demais de perigos e descontentamentos. Do contrário, os livros de Oz provavelmente seriam muito tediosos. E Oz não é nem mesmo a ideia baumiana de eutopia ou bom lugar, embora de muitos modos possa ser melhor do que os Estados Unidos de sua época. A diferença básica entre o mundo que os leitores percebem e o mundo na Terra de $\mathrm{Oz}$ é, claro, que em Oz existe mágica de verdade, de forma a impossibilitar reproduzir o que se passa lá no mundo real; é matéria de fantasia. Com a ciência e a tecnologia disponíveis na época do autor, e mesmo na nossa, não há modo de substituir todas as partes de um ser humano por estanho, nem de fazer um homem de palha ganhar vida. As pessoas também não podem permitir aos animais pensar racionalmente, agir a partir deles e comunicá-los em inglês para a espécie humana. Portanto, Oz é de fato o que J.R.R. Tolkien chama de "mundo secundário", bastante distinto daquele por ele chamado de "mundo primário", no qual pessoas reais vivem (36). Na verdade, como a concepção que Baum faz de $\mathrm{Oz}$ muda de livro para livro, pode ser mais preciso afirmar que se trata de uma série de mundos secundários, distintos do mundo primário. E parece não haver meio de borrar as fronteiras entre $\mathrm{Oz}$ e o que Rogers chama de "o mundo cotidiano". Embora se possa alcançar Oz a partir do mundo real existente nos livros, não se pode alcançá-la a partir do mundo real onde pessoas reais vivem. Assim, serve como um espaço sagrado dentro dos livros de $\mathrm{Oz}$, mas como um espaço inatingível no mundo real (TUERK, 2007, p. 181-182, tradução de Carol Chiovatto ${ }^{9}$ ).

A argumentação de Tuerk aponta o percurso que queremos mostrar neste artigo: como a série de $\mathrm{Oz}$, e, notadamente, o primeiro volume, concebido como 
um conto de fadas que, ao mesmo tempo, recupera a ideia de uma utopia, acaba por ser considerada um dos grandes precursores da fantasia, então, ainda por ser sistematizada como nova categoria? A ideia de "mundo secundário" parece justamente servir de ponte para essas três tradições, uma vez que deriva, de certa forma, do ideal utópico de um mundo ainda por construir ou descobrir ao mesmo tempo que se organiza a partir de elementos mágico-sobrenaturais provenientes do maravilhoso. A fantasia, portanto, enquanto categoria narrativa muito mais recente e facilmente "mapeável", suscita algumas questões, particularmente por sua proximidade com as outras categorias comentadas até aqui. Para introduzila, recorre-se à Ursula Le Guin, célebre escritora de fantasia e ficção científica, que, em uma abordagem tanto metapoética quanto impressionista, lança-se ao mesmo questionamento:

O que é a fantasia? Em uma certa perspectiva, é claro, é um jogo: um puro simulacro, sem nenhuma reflexão por trás. [...] Noutra perspectiva, a fantasia continua sendo um jogo, mas [...] [é] arte, não uma diversão espontânea. Vista sob este ângulo, aparenta-se mais ao devaneio do que ao sonho. Ela representa uma outra abordagem da realidade, outra maneira de apreender a existência, outra maneira de enfrentá-la. A fantasia não é antirracional, mas para-racional; ela não é realista, mas surrealista, super-realista, uma intensificação da realidade. [...] A fantasia aproxima-se da poesia, do misticismo e da loucura, muito mais do que o faz a ficção naturalista. É um campo verdadeiramente selvagem, e aqueles que a percorrem têm interesse em não se crer fora de perigo, e seus guias, os escritores de fantasia, em levar o seu papel a sério (LE GUIN, 2016, p. 90-91, minha tradução ${ }^{10}$ ).

Nessa tentativa de apreensão do conceito, Le Guin (2016) não busca uma resposta definitiva, mas dá boas pistas, ao 1) contrapor a fantasia com a visão naturalista da realidade e, ao mesmo tempo, apresentá-la como uma visão não contrária, mas alargada do que consideramos real; 2) ao frisar seu caráter artístico, o que se revela importante ante o constante preconceito da crítica especializada em relação a essa categoria; 3) por fim, Le Guin (2016) destaca que a fantasia é não apenas uma "abordagem da realidade" e uma maneira de "apreender a existência", mas acima de tudo uma forma de enfrentá-la, ou seja, a fantasia longe de ser escapista - como tão constantemente a acusam - apresenta-se como uma via válida para criticá-la, analisá-la, interpretá-la. E, por esse caminho, a fantasia se aproxima bastante das outras vertentes do insólito ficcional aqui comentadas: a utopia e o maravilhoso. Isso porque, tal como a primeira, a fantasia busca imaginar outras possibilidades, outros mundos, outras vivências, melhores ou piores do que a nossa, no intuito de elucidá-la, criticá-la ou até de propor outras formas de estruturá-la. Por outro lado, tal qual o maravilhoso, a fantasia respeita a tradição, a cultura popular, recuperando elementos do imaginário e reorganizando-os em novas realidades. Logo, não parece exagero dizer que a fantasia bebeu dessas duas outras vertentes, estruturando-se, no entanto, de forma diversa. E, não por acaso, a origem da fantasia tal como a conhecemos hoje, surgida no fim do século XIX e começo do XX, coincidira com a publicação da série de L. Frank Baum. 
A esse respeito, vale destacar que em A Short History of Fantasy (MENDLESOHN; JAMES, 2009), os pesquisadores britânicos Farah Mendlesohn e Edward James, mencionam a série de $\mathrm{Oz}$ como uma das primeiras fantasias senão a primeira -, em seu sentido estrito, escrita por um autor estadunidense, como se lê no trecho a seguir:

L. Frank Baum americanizou a fantasia do outro mundo. A fantasia de portal era bem nova quando Baum escreveu O Maravilhoso Mágico de $\mathrm{Oz}$ (1900), o primeiro de uma longa série. Fantasias anteriores desse tipo, vindas do inglês, tendiam a ser bastante vagas quanto aos meios de transporte ao mundo fantástico, à localização desse mundo fantástico e à sua política. A Oz de Baum aparece em mapas (na verdade, é bem defensável que os dele tenham sido os ancestrais de todos os mapas que introduzem tantas trilogias de fantasia modernas). Em livros posteriores, sugere-se que Oz fica muito próxima ao Kansas. Pode-se alcançá-la numa casa arrastada por um furacão, ou descendo um rio de barco. Oz contém vários países, cada um com um regime diferente, e insinua-se um sistema econômico (MENDLESOHN; JAMES, 2009, p. 26, tradução de Carol Chiovatto $\left.^{11}\right)$.

Esse posicionamento também foi adotado por vários outros pesquisadores que se dedicaram a mapear esse modo narrativo (RUAUD, 2001, p. 28; BAUDOU, 2005, p. 36; BESSON, 2007, p. 96, MATANGRANO; TAVARES, 2018, p. 243). Susan Rahn afirma ainda a esse respeito que $\mathrm{Oz}$ é "não só o primeiro romance de fantasia escrito por um autor americano como o primeiro a criar um mundo imaginário distintamente americano" (RAHN, 1998, p. 7, apud CHIOVATTO, 2017, p. 27). Mas, afinal, para além da definição vaga de Le Guin (2016), em termos crítico-acadêmicos, como podemos delimitar o que é a fantasia?

No livro Fantástico Brasileiro, no capítulo dedicado à "alta fantasia", esse conceito é definido como a nomenclatura aplicada a "uma obra narrativa dedicada, sobretudo, a enredos passados em lugares imaginários, cujas leis diferem das que regem o mundo dito 'real' em, ao menos, uma instância, seja física, metafísica, religiosa, biológica etc." No mesmo texto, identifica-se ainda que, por isso, "em suas primeiras manifestações" apresentou-se por meio de "lugares utópicos", tais como os universos de Baum, Barrie e Lewis (MATANGRANO; TAVARES, 2018, p. 243), uma vez que até então essa era a concepção mais comum de "não lugar", ou melhor, de "outro lugar", o que culmina na ideia de "outro mundo". Numa explicação um pouco mais detalhada, pode-se dizer que:

A fantasia se define pela existência de outra realidade, chamada para fins didáticos de "mundo secundário", sendo o "mundo primário", ou de partida, a própria realidade (MARQUES, 2015, p. 16). Esse outro mundo tanto pode ser um local totalmente distinto, com leis físicas, químicas, geográficas e biológicas próprias (como é o caso da Terra-Média de Tolkien), quanto um espaço alternativo dentro do mundo primário (como é o caso dos lugares onde vivem os bruxos na série Harry Potter, de J. K. Rowling). A proximidade e/ou a relação com o mundo primário definiria 
quando se trata de uma alta fantasia (pautada inteiramente no mundo secundário), ou de uma baixa fantasia (centrada no contato e diálogo entre os dois) (MATANGRANO, 2019, p. 3).

Contudo, se por um lado a fantasia parece recuperar algo da utopia, também o faz em relação ao maravilhoso, categoria à qual pertencem os contos de fadas, aos quais Baum pretensamente filia sua série, como anteriormente já comentamos. Sobre essa relação, Marques (2015) comenta:

Propõe-se, portanto, a definição de um gênero aparentado com o maravilhoso e, consequentemente, com os contos de fadas, mas distinto deles, podendo-se, aliás, dizer que a fantasia é, simultaneamente, a exacerbação e a contraparte do maravilhoso. Exacerbação no sentido de que é o maravilhoso levado a outro nível, com a construção de um mundo coerente, diverso do Mundo Primário, ou seja, um mundo no qual as leis desse não explicam todos os fenômenos e no qual podemos encontrar seres e acontecimentos, aqui impossíveis. Contraparte porque enquanto o maravilhoso representaria uma espécie de integração, de harmonia, entre o "sobrenatural" e o Mundo Primário, a fantasia implica o outro, ou seja, ela exige a percepção das diferenças entre o "mundo real" e o "Mundo Secundário", que se tenha em conta o fato de eles não serem a mesma coisa, mesmo quando se interpenetram. O maravilhoso, em certo sentido, como se pode ver em relação aos contos de fadas, está mais preso ao "Mundo Primário", ainda é sua representação estilizada, enquanto a fantasia está livre para alçar voo e criar outro mundo (MARQUES, 2015, p. 16-17).

Podemos concluir, por conseguinte, ser natural a relação de O Maravilhoso Mágico de Oz (BAUM, 2014b) e suas sequências com esses três modos narrativos, uma vez que Baum os escreve em um momento de transição, quando a fantasia começa a se estabelecer como nova categoria, a partir de elementos "emprestados", por assim dizer, das utopias e dos contos maravilhosos, notadamente dos contos de fadas, mas também dos mitos e sagas, dos quais herda o viés heroico. Claro que a fantasia não se resume ou se restringe a isso, mas se insere nessa mesma tradição. Por isso, a fantasia se apresentaria, ao menos nesse primeiro momento, como uma categoria híbrida. Contudo, dada a mudança de foco, que não é mais apenas o maravilhamento destes ou a reflexão político-ideológica daquelas, mas sim o pleno exercício mental de se pensar outras sociedades, outras espécies sencientes e finalmente outros mundos. E, ao fio dos anos, a fantasia passa a adquirir autonomia constituindo um novo modo narrativo.

\section{Quais inovações de Baum permitem ler a série como uma fantasia?}

Para responder a essa pergunta, relembremos sumariamente o enredo do primeiro volume da série. O Maravilhoso Mágico de Oz (BAUM, 2014b) conta a história de Dorothy, uma garotinha do Kansas que, um dia, levada por um ciclone, chega à Terra de $\mathrm{Oz}$, onde ela conhece três personagens imortalizadas no imaginário contemporâneo: o Espantalho, o Leão Covarde e o Homem de Lata, entre outras de menor participação. Cada uma dessas personagens é 
introduzida em uma situação episódica, que se repete a partir de uma estrutura reconhecível, em geral, por três vezes, como típico em grande parte dos contos de fadas tradicionais, seja nos autorais ou naqueles colhidos da tradição oral. Os elementos tipicamente norte-americanos, por sua vez, para além da ambientação inicial, são utilizados para compor o caráter da protagonista, enquanto as outras personagens retomam o espírito dos contos maravilhosos.

Dorothy sonha em voltar para a sua casa, pois "Não há lugar como o lar" (BAUM, 2014b, p. 37), como diz, em uma valoração patriótica de seu Kansas natal, a despeito do flagrante contraste entre as duas terras: o Kansas é descrito como cinza e árido, enquanto Oz é brilhante, colorido e verdejante. Apesar disso, para ela, os Estados Unidos é um "país civilizado", em oposição a $\mathrm{Oz}$ que não o seria, pois, em seu raciocínio, somente isso explicaria a existência de magos, bruxas e toda sorte de seres feéricos. A garotinha é destemida e proativa, agente de seu próprio destino, ao contrário de outras protagonistas de histórias infantis contemporâneas ou anteriores, como Alice e Wendy ${ }^{12}$. Ou seja, apesar das inúmeras maravilhas da Terra de Oz, Dorothy continua a ver sua pátria natal como um lugar superior e desejável, relação que, no entanto, será desconstruída ao longo da série, conforme a protagonista se encanta cada vez mais com aquele universo - sem deixar de admirar sua terra natal - até o ponto de se mudar definitivamente para ele com seus tios.

Por conta dessa relação de Dorothy com seu país, subverte-se em Oz a ideia de utopia, enquanto lugar idealizado e almejado. Afinal, mesmo sendo um lugar melhor, posto que mais bonito e mais agradável do que o Kansas, Oz não é o lugar desejado por Dorothy. Seu impulso é voltar para casa. Claro que, tal como esperado em uma narrativa utópica, as qualidades de $\mathrm{Oz}$ se contrastam com os problemas norte-americanos, levando à reflexão. Baum, porém, aproveita essa deixa para levantar a questão nacionalista, motivo pelo qual seu livro foi lido como uma utopia americana. Vale lembrar quanto a isso, a percepção de Manguel (2014) de que não raro nas grandes narrativas de jornadas, e na Odisseia, em particular, a grande questão é justamente o retorno: "O maior explorador é alguém que não deseja verdadeiramente explorar, que pretende voltar para casa e aí ficar” (2014, p. xvi). E Oz se inscreve nessa longa tradição, que remonta a Homero, de viagens extraordinárias cujo objetivo é reencontrar o caminho para o próprio lar. Por sua vez, como apontado antes, em seu enredo é possível identificar a atmosfera feérica e a narrativa episódica dos contos de fadas tradicionais, reconhecíveis a partir de estruturas elementares, além daquilo que se poderia chamar de certo nonsense típico do maravilhoso, na medida em que diversas coisas acontecem, sem qualquer explicação lógica ou racional, por vezes contrariando as próprias regras que regem aquele mundo, sob a simples explicação de que as coisas são como são.

A principal diferença entre $\mathrm{Oz}$ e os contos de fadas, por outro lado, permanece na complexidade narrativa, pois mesmo se estruturando a partir de princípios reconhecíveis, há níveis mais aprofundados e sobreposição de episódios, resultando numa narrativa não só mais desenvolvida do que a média dos contos maravilhosos, mas também mais extensa. A elaborada construção de 
mundo, bem como sua autonomia em relação ao dito "mundo real", é o que o aproxima dos mundos concebidos nas obras de fantasia. Oz não é simplesmente um lugar mágico absurdo como o País das Maravilhas de Carroll, do mesmo modo também não é irreal, tampouco um sonho ou um pesadelo, mesmo se o filme de 1939, contrariando o final do livro, assim o tenha feito, transformando $\mathrm{Oz}$ e seus habitantes em um sonho de Dorothy.

Na série de livros, o País de Oz existe como uma espécie de outra "dimensão", acessível por portais sem que nunca se saiba como descobri-los, mas que sempre estãolá. Nesse sentido, éo mesmo caso de Nárnia, de C. S. Lewis (2005). É por isso que $\mathrm{Oz}$ pode ser considerado como um dos primeiros Mundos Secundários, segundo a forma tal como é entendido hoje: um território geograficamente complexo, com vários povos diferentes, reinos, governos, raças sencientes, fauna e flora particulares e muitos problemas cotidianos previstos em uma sociedade grande e heterogênea, mesmo $\mathrm{Oz}$ sendo uma espécie de utopia ou mesmo, por vezes, de eutopia, onde as pessoas, a priori, não podem morrer, tampouco envelhecer.

Esse lugar existe de maneira independente do mundo dito "real", que, por vezes, não é sequer citado, como no caso do segundo livro da série, cuja história se passa depois do retorno de Dorothy aos Estados Unidos. No sexto volume, A Cidade das Esmeraldas de Oz (1910), Dorothy e sua família se mudam para Oz para sempre. Todavia, mesmo sendo um mundo autônomo, a Terra de $\mathrm{Oz}$ reproduz muitos dos traços de nosso próprio universo, afinal, como comenta Fonstad (2004, p. ix), "Tolkien explicou que, para dar credibilidade a uma terra imaginária (e à história que se passa nela), o Mundo Secundário precisa ter a 'consistência interna da realidade.' Quanto mais um Mundo Secundário difere do nosso Mundo Primário, mais difícil é manter essa credibilidade”.

Figura 1: Mapa da Terra de Oz, originalmente publicado em O Maravilhoso Mágico de Oz (1900), reproduzido na segunda capa da edição anotada comemorativa do centenário

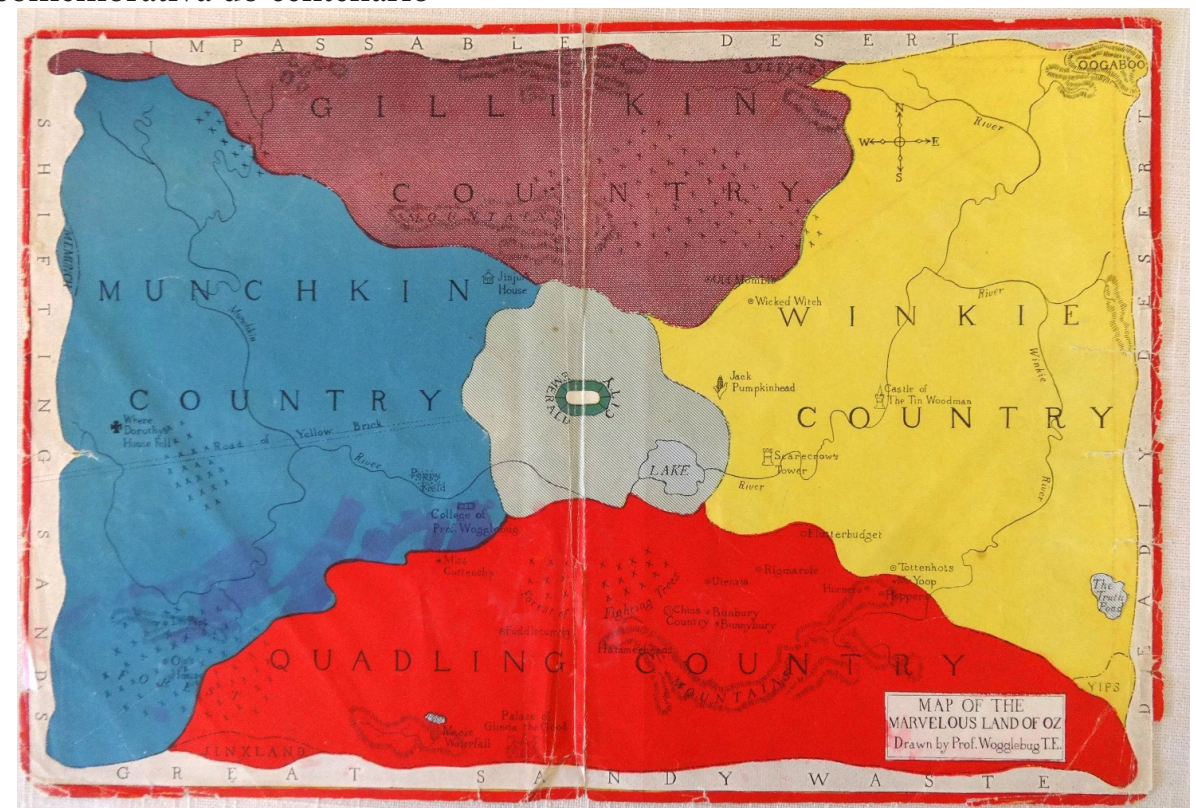

Fonte: Baum (2000) 
Logo, de acordo com Tolkien, o sucesso de um "Mundo Secundário" depende justamente da crença do leitor durante o ato da leitura, para possibilitar uma plena imersão no universo imaginário. Para ele, essa é uma habilidade inata nas crianças, que também se estende a alguns adultos. A boa fantasia seria justamente aquela que consegue se fazer crível, e o "subcriador bem-sucedido" seria aquele capaz de conceber uma nova realidade na "qual nossa mente pode entrar", aceitando os novos paradigmas daquele mundo como uma "verdade". Essa sensação deve durar "enquanto estamos, por assim dizer, do lado de dentro. No momento em que surge a incredulidade, o encanto se rompe; a magia, ou melhor, a arte, fracassou. Então estamos outra vez no Mundo Primário, olhando de fora o pequeno Mundo Secundário malsucedido" (TOLKIEN, 2006, p. 4344). Essa ancoragem na dita realidade, por sua vez, é tanto um desafio, como Tolkien (2006) mostra, quanto uma vantagem, pois, segundo Manguel (2014, p. xxvii), a "geografia imaginária também nos permite resolver problemas políticos complexos, ou pelo menos refletir melhor sobre eles", uma vez que se trata de um universo "sem fronteiras", onde é possível criar "sociedades perfeitamente eficazes" ou "perfeitamente atrozes".

No que diz respeito à relação do mundo de Baum com o real, podemos considerá-lo um mundo paralelo ao nosso, segundo a tipologia proposta por Antonio Sánchez-Escalonilla (2009, p. 92, minha tradução ${ }^{13}$ ), ou seja, "tem uma existência descontínua e autônoma em relação ao mundo primário dos protagonistas", no caso os Estados Unidos. Esse tipo de universo se contrapõe à ideia de mundo alternativo, que, em resumo, se definiria como um mundo secundário semelhante ao primário, salvo por "alguns detalhes" (idem, p. 93) - frequente em obras retrofuturistas, por exemplo -, e ao mundo de fronteira, construído em continuidade ao primário e acessível por determinadas passagens (idem, p. 91) - como acontece nos livros da saga Harry Potter, na qual o mundo mágico revela-se um continuum do nosso. Esse autor também frisa que $\mathrm{Oz}$ é essencialmente utópico e ucrônico, no sentido estrito desses dois termos, isto é, um lugar além do tempo e do espaço em relação ao universo primário.

Esse mundo é apresentado de maneira bastante inovadora por um mapa elaborado da Terra de $\mathrm{Oz}$ (Figura 1), publicado junto ao primeiro volume da série e complementado por um segundo mapa (Figura 2), a partir do terceiro livro, Ozma de Oz (1907), ainda mais detalhado, no qual estão representadas as terras vizinhas, povoadas por amigos e inimigos dos habitantes de Oz e cenário de vários outros romances do autor não pertencentes à saga principal, muitas vezes, com crossover de personagens da série de $\mathrm{Oz}^{14}$. 
Figura 2: Mapa expandido da Terra de $\mathrm{Oz}$ e arredores, originalmente publicado em Ozma de Oz (1907), reproduzido na terceira capa da edição anotada comemorativa do centenário

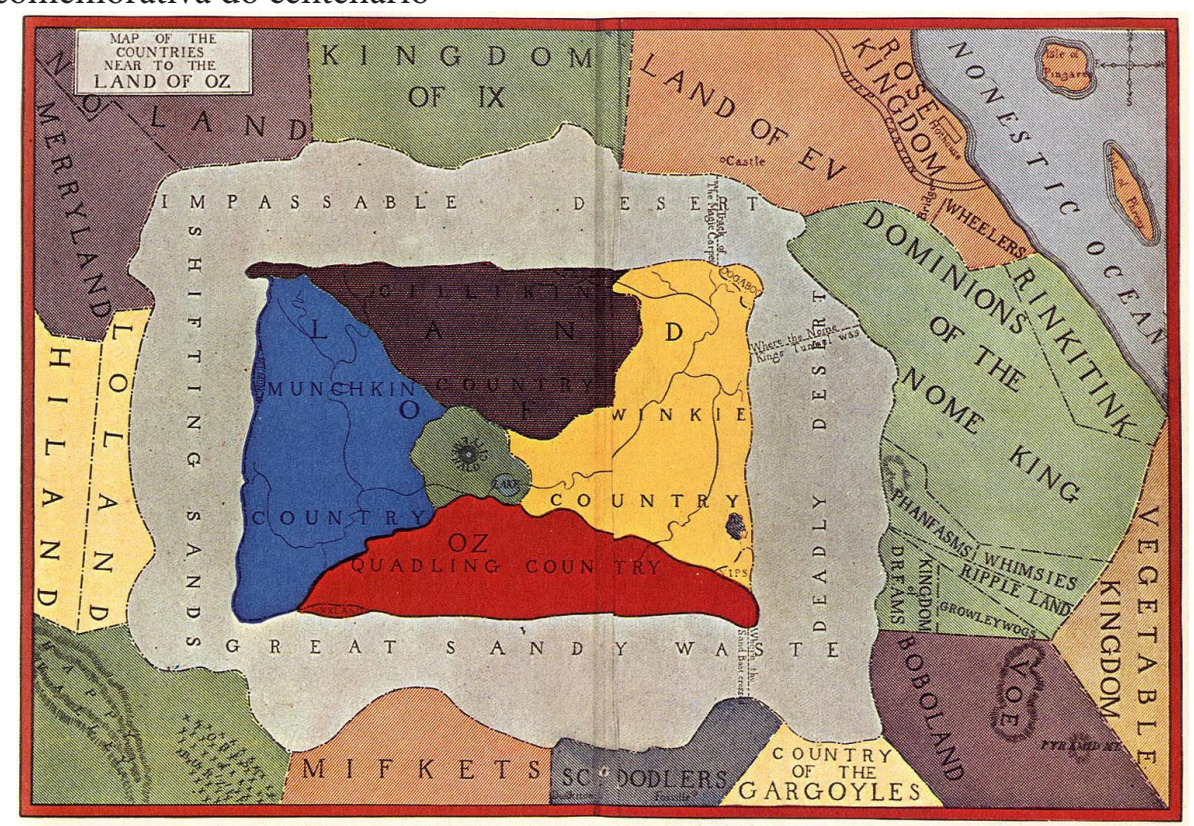

Fonte: Baum (2000)

Claro que antes de $\mathrm{Oz}$, outras obras já haviam proposto mapas para terras ficcionais. Há mapas da Utopia de More e da Liliput, de Swift. Manguel (2014, p. xiv), inclusive, comenta a esse respeito sobre o quanto é "antiga a necessidade de inventar países e depois dizer como o autor os encontrou", apresentando "mapas, por mais rudimentares que sejam". Contudo, antes de Baum, nunca se havia feito um mapa para um mundo secundário, isto é, para um lugar que não apenas estivesse "escondido" dentro do nosso mundo, mas que fosse em si mesmo um mundo à parte. $\mathrm{O}$ mapa serve, portanto, para mostrar a materialidade desse novo lugar, subcriado, na expressão de Tolkien, pois, como defende Julie Garel-Grislin (2019):

Longe de impor ao leitor uma figura definitiva que frearia sua imaginação, "o mapa, mesmo fictício, sugere algo além da ficção, que seria o próprio real, em sua extensão sem limites" [Pierre Jourde, Géographies imaginaires, 1991, p. 104]. É precisamente porque ele imita a objetividade da representação cartográfica "realista" ordinária que o mapa imaginário eleva o universo fictício que descreve ao nível de mundo consistente e autônomo - por onde se ilumina a paradoxal "necessidade de mapas" de alguns criadores de narrativas (GAREL-GRISLIN, 2019, p. 30, minha tradução ${ }^{15}$ ).

Portanto, embora não seja uma característica necessária à fantasia, tampouco seja dela uma exclusividade, a presença de mapas acaba por se revelar uma forma bastante frequente e inovadora desse modo narrativo de apresentar novas realidades, seja dentro do mundo real, seja em universos secundários. No entanto, no contexto da publicação de $\mathrm{Oz}$ a ideia de "mundo secundário" 
ainda não estava sistematizada, faltavam cerca de trinta anos para Tolkien refletir e escrever sobre o tema. Por isso, não raras foram as especulações sobre onde ficaria Oz e acerca dos lugares em que Baum teria se inspirado para criá-lo. Para começar a responder a essas questões, analisemos brevemente os dois mapas publicados nos livros de Baum.

Onde fica Oz? A questão dos mapas, uma inovação da fantasia, herdada das utopias

Como podemos ver, em ambos os mapas, ao centro, encontra-se a Terra de $\mathrm{Oz}$, descrita como "Um país Fantástico", representado com suas cinco partes: a Província dos Munchkins a leste (onde tudo é azul, a cor das roupas, as casas e até mesmo a vegetação); a Província dos Winkies a oeste (identificado pela cor amarela); a Província dos Gillikins ao norte (roxa); a Província dos Quadlings ao sul (vermelha); por fim, ao centro, localiza-se a Cidade das Esmeraldas onde tudo é verde. Ao redor de $\mathrm{Oz}$, fica um deserto teoricamente intransponível, mas que é atravessado de tempos em tempos mesmo assim. Oz se localiza no continente que ficou conhecido como Nonéstica, composto pela Província de Oz e por muitos outros territórios menores. Por sua vez, o continente é contornado pelo Oceano Nonéstico ${ }^{16}$, cujo nome evoca a expressão latina Non est, literalmente, "não é", "não há" ou, simplesmente, "não existe", o que já dá o mote de que se trata de um país imaginário e, portanto, secundário.

Não obstante essa pista dada pelo nome, não foram poucos os comentadores contemporâneos ao livro que se esforçaram para relacionar $\mathrm{Oz}$ com outros lugares de nosso globo, buscando sua localização exata. Escrito antes de a ideia de "Mundo Secundário" ter sido concebida, a ideia é que, mesmo sendo um país inventado, Oz deveria obrigatoriamente ficar em algum lugar físico, como a ilha de Robinson Crusoe, situada em algum ponto do Atlântico, na proximidade das Antilhas. A partir disso, uma das principais teorias quanto à localização de Nonéstica se resume a associá-lo à Austrália, posto que se trate de uma grande extensão de terras, com muitos desertos e rodeada por águas oceânicas.

Essa teoria teria se difundido após a publicação do terceiro volume da série, Ozma de $\mathrm{Oz}$, que se inicia com a heroína numa viagem transatlântica através do Pacífico, indo de seu Kansas natal até a Austrália, onde tem alguns parentes (BAUM, 2014c, p. 16). Uma tempestade acaba por jogá-la na água e, depois de passar algum tempo à deriva, Dorothy e Billina, uma galinha amarela, chegam às praias do continente de Oz. Ou seja, de algum modo, a garota saiu do Pacífico e entrou no oceano Nonéstico. Todavia, o mesmo acontece no Kansas via tornado, no primeiro livro, e via uma fenda após um terremoto no quarto volume, o que deixa claro que há múltiplas formas de acessar $\mathrm{Oz}$, as quais não têm, necessariamente, a ver com o local onde se está, mais ou menos como acontece nos livros da série As Crônicas de Nárnia. Mesmo assim, a teoria australiana não é fortuita e parece ter sido aventada pelo próprio Baum como explicação possível, mas descartada, como comenta Hearn (2000): 
A teoria mais popular acerca da verdadeira localização de $\mathrm{Oz}$ é em algum lugar do Pacífico Sul. Na peça de Baum The Girl from Oz (1909), que não chegou a ser produzida nem publicada, uma personagem diz que Oz é "uma ilha distante no Pacífico". No conto "Nelebel's Fairyland" [A terra feérica de Nelebel] (The Russ, June 1905), a heroína viaja rumo ao leste a partir da Floresta de Burzee, que fica no mesmo continente de Oz, para a Baía de Coronado, na Califórnia. Durante uma viagem transoceânica para a Austrália em Ozma de Oz (1907), Dorothy acaba presa no litoral do continente onde fica Oz. Algumas pessoas, como a membro do Oz Club Sonia B. Brown em "Have We Discovered Oz?" [Acaso nós achamos Oz?] (The Baum Bugle, Spring 1980), defenderam, de modo não muito convincente, que Oz é a Austrália (HEARN, 2000, p. 30, tradução de Carol Chiovatto ${ }^{17}$ ).

É interessante pensar que as incessantes teorias para tentar "descobrir" a "real” localização da Terra de $\mathrm{Oz}$, muitas aventadas pouco após a publicação do primeiro volume, demonstram o quanto a crítica da época não estava familiarizada com a ideia de mundos secundários e apontam uma mudança de paradigma; uma nova forma de narrativas nascia, mas não um novo tipo de "contos de fada", como Baum interpretava, e sim um novo modo narrativo: a fantasia. Para o pensamento da época, porém, um lugar - mesmo sendo um lugar imaginário - precisava estar em alguma parte. Logo, Oz não era lido como Alice, cujo País das Maravilhas sabidamente se passava em sonhos, ou mesmo como os contos de fadas tradicionais, cujas histórias acontecem em um passado remoto e ucrônico, mas não utópico, posto que entendido como alguma parte da Europa em tempos imemoriais. Também não se confundia com o mundo dos goblins de George MacDonald (1824-1905), outro dos ditos "pais" da fantasia, uma vez que sua terra feérica se encontrava abaixo do nosso mundo, acessível por uma passagem ínfera, como se numa releitura do Hades clássico.

$\mathrm{Em} \mathrm{Oz}$, a lógica aplicada era diferente, mais próxima à da ilha de Robinson Crusoe, ou de outras narrativas de viagem, remontando mesmo à Odisseia homérica. Se Robinson se perdeu numa ilha no Atlântico, esta haveria de existir, assim como deveriam ter base real as inúmeras localidades visitadas pelo filho de Laerte; do mesmo modo, se Dorothy foi levada por um ciclone, este a levou para algum lugar passível de ser encontrado, seja no interior do país, seja no oceano Pacífico circunvizinho. Esse afastamento de $\mathrm{Oz}$ dos contos de fadas tradicionais e consequente aproximação das narrativas de viagem parece ser um forte indício da transição do maravilhoso para a fantasia ${ }^{18}$. Vemos o mesmo tipo de movimento em livros como os de William Morris (1834-1896), anteriores aos de Baum, onde também há uma viagem que leva a um mundo mágico desconhecido. Esse será igualmente o caso da Nárnia de C. S. Lewis. Por fim, na Terra-Média tolkieniana vê-se o desprendimento total do nosso mundo primário. Esse mundo subcriado existe de forma completamente autônoma, sem o olhar estrangeiro - como o de Dorothy ou dos irmãos Pevensie dos livros de Lewis - para apresentá-lo ou mediar o novo para o leitor. Em Tolkien, a necessidade de se entender onde fica o mundo é substituída pelo impulso de entendê-lo por e em si mesmo.

Para além da teoria de $\mathrm{Oz}$ se localizar no Pacífico ou ter sido baseado na Austrália, houve também quem o lesse como uma parte perdida do próprio 
subcontinente norte-americano. Em seu estudo $\mathrm{Oz}$ in perspective: Magic and Myth in the L. Frank Baum Books, Richard Tuerk (2007) reune algumas das teorias aventadas na época, como vê nos seguintes trechos, reforçando a curiosidade - e mesmo incompreensão - dos leitores da época ante um mundo inteiramente novo:

De acordo com Raylyn Moore, o fato de Oz ser cercada por desertos "sugere o paraíso não descoberto que poderia ser um oásis no coração do próprio Grande Deserto Americano, se tal deserto existisse na escala imaginada pelo cartógrafo e pelos primeiros exploradores" (96). De acordo com Michael O. Riley, antes da publicação de Tik-tok of Oz [Tik-Tok de Oz], em 1914, "a impressão mais geral a respeito da localização de $\mathrm{Oz}$ havia sido a de que está escondida no nosso mundo, difícil de se chegar, mas uma parte maravilhosa e inexplorada dos Estados Unidos" (187). Como Dorothy vai a $\mathrm{Oz}$ pela primeira vez carregada por um tornado, tais ideias parecem plausíveis no primeiro livro da série. No entanto, na segunda vez, ela chega a $\mathrm{Oz}$ como resultado de uma tempestade no mar quanto está a caminho da Austrália, tornando difícil aceitar Oz como parte dos Estados Unidos. Em vez disso, a Oz de Baum aparentemente existe num tipo de espaço muito diferente daquele no qual as pessoas realmente vivem, e muito diferente dos Estados Unidos na época do autor, um lugar onde existe magia [...]. Moore reconhece que $\mathrm{Oz}$ também se assemelha a "ilhas míticas pelas quais procuraram exploradores" (98), uma ideia que sugere que se deve pensar em $\mathrm{Oz}$ como existindo fora do mundo físico como o conhecemos, um lugar "mítico" em vez de real. [...] Moore está certo quanto a semelhança de $\mathrm{Oz}$ com as "ilhas míticas"; o trabalho de Baum provavelmente descende, ao menos em parte, de [Christopher] Cranch, [Jonathan] Swift e [Daniel] Defoe, tendo assim antecessores tanto americanos quanto europeus. De qualquer modo, na "ilha" de Baum cercada não por água, mas por um deserto - a magia existe. Como diz Trot em Magic of $\mathrm{Oz}$ [A Magia de $\mathrm{Oz}$ ], em Oz "a magia é tão comum" (145) (TUERK, 2007, p. 179-180, tradução de Carol Chiovatto ${ }^{19}$ ).

Mais interessante e mais lógica, foi a vertente que leu o mundo de Baum como uma versão inspirada na Atlântida, um dos mais antigos continentes "perdidos", originários das mitologias clássicas, no caso a grega. Sua história remonta aos diálogos platônicos, nos quais o célebre filósofo a descreveu, bem como a seu povo. Segundo o mito, portanto, o continente seria uma contraparte da sociedade ateniense, sua inimiga, que teria sucumbido frente a um tsunami. No verbete "Platão" do Dicionário das Utopias, encontra-se a seguinte definição:

A Atlântida, distopia marítima, imagem de um Estado pletórico, inorgânico e confuso, apesar da sua estrutura de aparência racional, é a imagem da Atenas contemporânea [de seu tempo, em contraponto à ideia de uma eutópica Atenas mítica], imperialista e corrupta. Desapareceu por entre as vagas, e a cidade primeira, como se o curso do tempo tivesse nascido na guerra que tinha ligado o seu destino ao resto do mundo, viu o seu território ser devastado e a sua população ser destruída pelo dilúvio, tendo apenas os egípcios para guardar a lembrança da sua perfeição (BERTRAND, 2009, p. 205). 
Também no caso de Atlântida, muito se especulou acerca de sua localização. Muitos a situavam em meio ao oceano Atlântico, do qual seu nome deriva, enquanto outros a colocavam no meio do Mediterrâneo, e, portanto, sem proporções de fato continentais. Assim como $\mathrm{Oz}$, a Atlântida platônica tem um caráter utópico intrínseco, mesmo se, por vezes a forma como ambos foram representados oscile entre a distopia e a eutopia, como antes comentado. Para além dessas semelhanças pontuais, outro argumento que justificou tal aproximação se deve ao vínculo de Baum com a Sociedade Teosófica ${ }^{20}$, que parecia ter grande interesse pelo continente descrito por Platão.

Figura 3: Carte de l'Atlantide: d'après Platon et Diodore [Mapa da Atlântica segundo Platão e Diodoro] (1775)

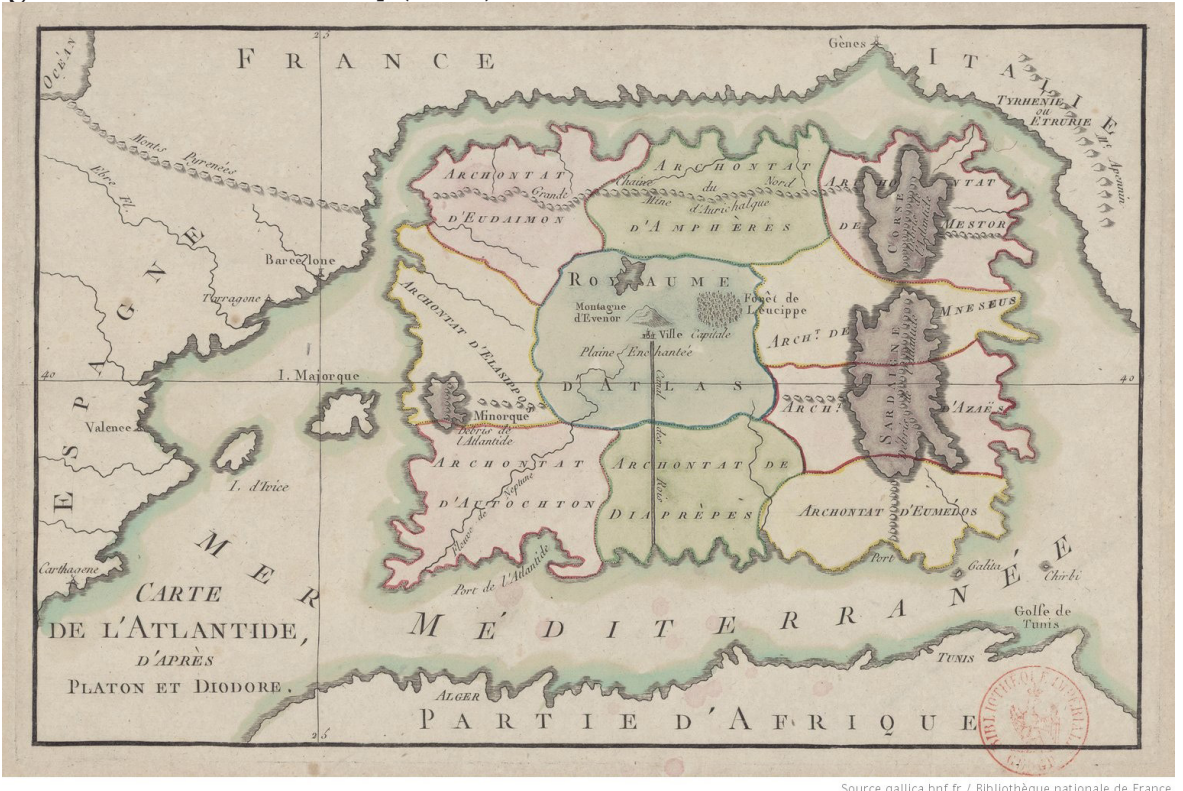

Fonte: Cartografista anônimo (1775), disponível no site da Biblioteca Nacional da França em: https://gallica.bnf.fr/ark:/12148/btv1b8495370s.

Uma inspiração provável para $\mathrm{Oz}$ foi o lendário continente de Atlântida. Platão falou dessa ilha mítica situada na boca do Mediterrâneo, de onde se diz que toda a filosofia, religião e cultura ocidentais se originam, mas que acabou sendo consumida pelo mar. Atlantis (1882), de Ignatius Donnelly, fez muito para reviver o interesse no mito na época de Baum; e a Irmandade Ramayana, o ramo da Sociedade Teosofista em Chicago à qual Baum pertencia, seguia o que chamava de a antiga Irmandade Atlanteana [sic] de Hermes. Seu líder, o Dr. William P. Phelon, alegava poder contatar Atlântida em transe. Matilda Joslyn Gage, sogra de Baum, acreditava ser um sacerdote atlanteano reincarnado! $\mathrm{Oz}$, como Atlântida, é uma terra que o Tempo esqueceu, onde bruxas e magos ainda habitam e a "civilização" ainda não invadiu. Sob o nome Floyd Akers, em The Boy Fortune Hunters in Yucatan (1910), Baum brincou com a crença de que sobreviventes de Atlântida estalebeceram-se na América Central (HEARN, 2000, p. 30, tradução de Carol Chiovatto ${ }^{21}$ ). 
Mas, para além dessas coincidências interessantes, bastante pontuais e circunstanciais, poucos elementos textuais aproximam $\mathrm{Oz}$ de Atlântida. Há uma única citação referente ao país submerso, encontrada no quarto volume da série, Dorothy e o Mágico em Oz, na qual um dragonete afirma descender da grande nobre linguagem atlante que remonta a vinte mil anos antes quando os humanos não existiam (BAUM, 2015, p. 142). Contudo, se não de forma direta, Atlântida parece ter inspirado Baum ao menos por meio de sua representação cartográfica. Quando comparamos os mapas de $\mathrm{Oz}$ com alguns dos mapas imaginários da cidade perdida e, especificamente, com um mapa em particular, intitulado Mapa de Atlântida segundo Platão e Diodoro, de 1775 (Figura 3) ${ }^{22}$, vemos que as similaridades são espantosas.

Figura 4: Comparação entre o Mapa de Atlândida de 1775 e o mapa da Terra de Oz e seus arredores publicado em Ozma de Oz em 1907

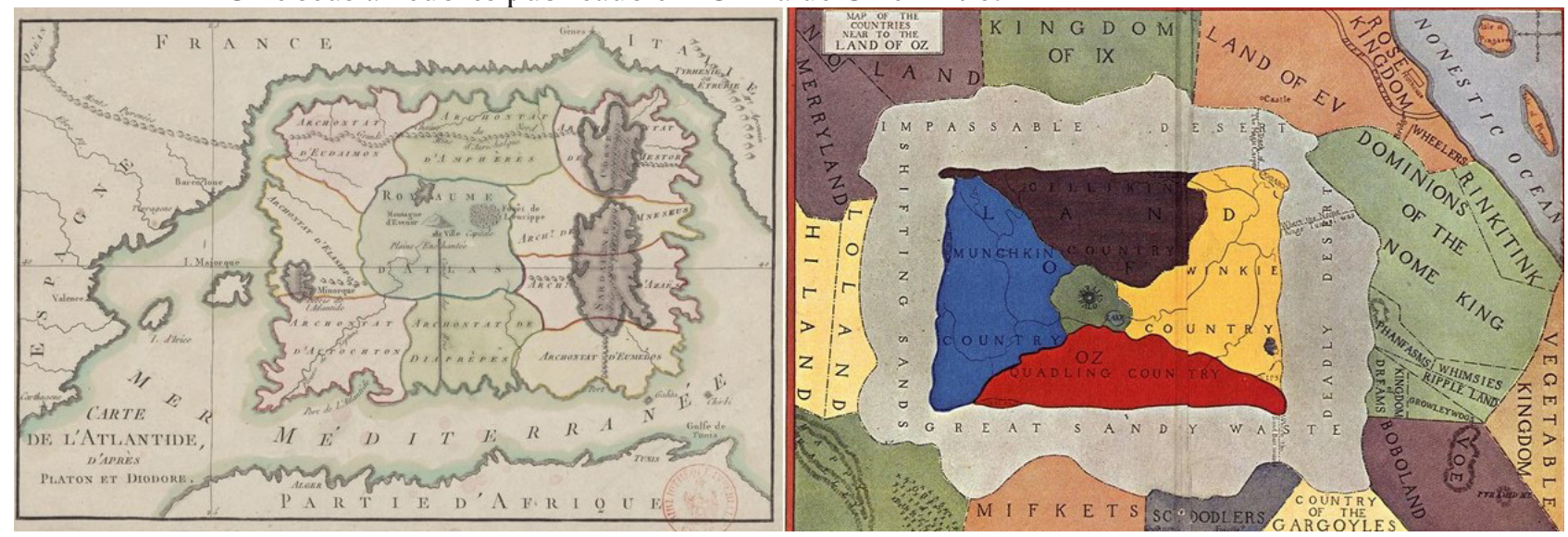

Fonte : Elaborada pelo autor a partir da Carte de l'Atlantide: d'après Platon et Diodore (1775) e de Baum (2000)

Como podemos ver, esse mapa propõe que Atlântida longe de ser um continente era antes apenas uma grande ilha retangular situada no Mar Mediterrâneo, ao sul da atual França, a oeste da Itália de hoje e a leste da atual Espanha. Segundo essa teoria, dessa grande ilha teriam sobrevivido algumas partes ainda hoje visíveis, como a Córsega francesa, a Sardenha italiana e a Minorca espanhola. Claro que não se pretende defender aqui que Nonéstica é Atlântida; contudo, a similaridade entre o mapa criado da série de Baum (2000) e o mapa de 1775 é patente (Figura 4): vê-se uma porção de terra de atípico formato retangular, com um reino ao meio - representado em verde -, em torno do qual estão outros pequenos estados (nove ao todo, e não quatro, como em Baum). A diferença é que se na Atlântida do cartografista anônimo são águas circulando o país - em torno das quais se vislumbram países -, na cosmogonia de Baum, a Terra de Oz é circundada por um deserto e, este, por sua vez, por outros países menores que, finalmente, são rodeados por água. De pequenas sinuosidades no relevo da fronteira até algumas cores em comum, tudo no mapa de 1775 parece se refletir no de $\mathrm{Oz}$, que inclusive parece estar espelhado como uma contraparte do continente perdido. 
Oz, portanto, mesmo sendo outro mundo, foi claramente inspirado em nosso mundo e em outras representações espaciais imaginárias. Talvez daí derive sua riqueza e diversidade. Esse país fantástico, como o chama Baum, recupera a forma da Atlântida retratada em 1775, bem como alguns das ilhas do oceano Pacífico, ao mesmo tempo em que se revela um mundo feérico da tradição celto-germânica e recupera traços dos ideais republicanos norte-americanos. Nesse amálgama de referências, surge algo novo. Onde Baum viu um novo tipo de conto de fadas, seus primeiros comentadores identificaram uma utopia, a crítica de hoje percebe o florescimento de uma nova categoria que suplantaria, em muito, o maravilhoso em número de publicações e em popularidade ao longo do século XX: a fantasia.

\section{O conto de fadas moderno e utópico de Baum, o germe da fantasia contemporânea}

Essa construção de mundo tão detalhada, como se depreende dos mapas, revela-se como elemento base da chamada high fantasy (alta fantasia) que só seria estruturada criticamente muitos anos depois. Aliás, como antes mencionado, se hoje pensamos nos mapas como parte essencial das fantasias e, particularmente, das altas fantasias, essa tradição em grande parte foi inaugurada por Baum. Tolkien tornou-se célebre nesse sentido, mas não só ele. Quase todas as obras que se the sucederam, de autores como Terry Brooks, Raymond E. Feist, George R. R. Martin, Steven Erikson entre outros, organizam seus mundos a partir de mapas que os tornaram "visíveis" aos olhos dos leitores bem antes dos filmes. E Baum fez mapas bem antes de todos. É claro, não é a existência de um mapa que fez de Oz uma fantasia, mas o mapa parece constituir uma consequência da elaboração desse mundo secundário complexo. E isso, sim, é uma característica da alta fantasia.

Por outro lado, as histórias de Oz não deixam de se parecem bastante também com contos de fadas na medida em que são narrativas episódicas, cujos problemas são facilmente resolvidos por personagens frequentemente tipificados. Em suma, se verificarmos item a item, quase sempre é possível constatar que os episódios seguem funções narrativas propostas por Vladimir Propp (2010) e revistas por Todorov (2008) para identificar o maravilhoso. Maria Zilda Cunha identifica algumas dessas funções no terceiro livro, que, segundo ela, é o que melhor se adequa ao modelo do conto maravilhoso: "As experiências múltiplas na trama são vividas por vários heróis. As personagens, nesta história, em número maior do que nas anteriores, desenvolvem determinadas funções. Funções que foram apontadas no estudo de V. Propp (1972) como constantes na estrutura dos contos maravilhosos" (CUNHA, 2014, p. 211). Por outro lado, Baum também segue as estruturas identificadas por Joseph Campbell sobre a jornada do herói épico (cf. TUERK, 2007), tema muito recorrente nas fantasias subsequentes, notadamente a partir de Tolkien e sucessores, como Brooks e Feist.

Além disso, esse mundo guarda o elemento feérico como explicação para quase qualquer acontecimento: um objeto pode adquirir vida em qualquer momento, por exemplo. Às vezes, com uma explicação narrativa detalhada, em 
outras, não há qualquer justificativa. Por exemplo, há o Pó da Vida utilizado no segundo volume da série para dar vida ao Gumpo (uma espécie de ser composto por diversos objetos em um tipo de bricolage), e também ao Cavale e ao Jack Cabeça-de-abóbora, mas não há nenhuma explicação concernente ao porquê de o Espantalho ter se tornado um ser animado. Um dia, ele passa a ver e se percebe vivo, assim que seus olhos são pintados no saco utilizado para fazer sua cabeça. Desse dia em diante, ele passa a sentir, a pensar e, consequentemente, a falar. O curioso é que nunca são levantadas questões quanto aos motivos dessas mudanças e transformações. E tudo é explicado de maneira genérica pelo fato de a Terra de $\mathrm{Oz}$ ser "um mundo fantástico" e também pela magia das fadas que, outrora, encantaram aquele universo (informação mencionada de passagem à medida que o universo de Baum se expande e ultrapassa os primeiros livros da série principal). Ou seja, no mundo de Oz tudo é explicado simplesmente por sua magia, que não é sistemática. Há vários elementos e situações tão inexplicáveis quanto aceitáveis.

O nonsense faz parte da lógica interna desse mundo que, na verdade, não tem lógica, se analisado pelos padrões de nossa realidade. A princípio, em $\mathrm{Oz}$ tudo pode acontecer de qualquer maneira, sem grandes preocupações com as leis básicas que regem nosso mundo, como as da física, da química e da biologia. E, no entanto, em meio ao aparente caos, destacam-se algumas sistematizações, como aponta Hearn (2000):

Evidentemente, há limitações na magia de Oz, pois mesmo um mundo imaginário precisa ter regras estabelecidas. George MacDonald disse, em “The Fantastic Imagination” [A Imaginação Fantástica], em A Dish of Orts: "Uma vez inventado seu mundo, a mais alta lei em jogo é que deve haver harmonia entre as leis pelas quais o novo mundo começou a existir, e no processo da criação, o inventor deve manter essas leis em vista. No momento em que se esquecer de alguma delas, deixa a história, dentro de seus próprios postulados, inacreditável. Para conseguir viver um momento num mundo inventado, devemos ver as leis que regem sua existência obedecidas. Uma vez quebradas, nós emergimos". Não se pode fazer tudo em Oz. Quando Dorothy em Glinda de Oz (1920) propõe que todos em $\mathrm{Oz}$ possam pedir por qualquer coisa que desejem, Ozma não apenas defende a ética puritana do trabalho, como prova julgar bem a natureza humana (HEARN, 2000, p. 298, tradução de Carol Chiovatto ${ }^{23}$ ).

Assim, se por um lado a mágica parece resolver tudo, como dito acima, por outro, a magia de $\mathrm{Oz}$ é regulamentada por duas grandes autoridades: Glinda e Ozma. A mágica explica o absurdo, mas ela também tem limitações e restrições, mesmo se o leitor não tem total acesso a esses mecanismos, ou seja, tal como costumava acontecer nos contos maravilhosos. Pode-se dizer que a principal diferença entre $\mathrm{Oz}$ e as fantasias posteriores é que estas, mesmo quando pensadas dentro de um sistema de magia abrangente, sempre respeitam um conjunto de leis e de regras pré-estabelecidos. Seu universo se comporta de modo diferente do esperado para um mundo secundário típico às fantasias modernas e contemporâneas, pois, nesses mundos de high fantasy, mesmo sendo organizados segundo um princípio mágico e/ou sobrenatural, as regras que o 
regem são muito mais precisas. Isto é, há uma estrutura organizacional por traz da tessitura narrativa que permite que algumas coisas aconteçam e outras não. Há mágica, é claro, mas também esta é tão sistematizada quanto as outras leis e regras, como a física e a biologia. Em Oz, há regras, mas não há uma lógica aparente, como em contos de fadas onde algo deve ser feito "porque sim" e não por qualquer motivo lógico.

Cada mundo secundário funciona a partir de alguns critérios estabelecidos a priori, mesmo se nem sempre estão explícitos logo de início. Por exemplo, na Terra Média o leitor sabe mais ou menos o que pode acontecer e o que é impossível. Em Baum, não dá para fazer esse tipo de dedução ou previsão. Em Tolkien, sabe-se que uma pessoa não consegue desaparecer de um ponto do mapa e aparecer em outro; mesmo os magos e divindades, precisam atravessar o espaço físico, seja a pé, a cavalo ou voando em águias. Em outras palavras, não há teletransporte. Em Oz, por outro lado, o teletransporte pode existir, se, por exemplo, um item mágico o possibilitar e como a criação de itens mágicos é virtualmente inesgotável, qualquer coisa se torna possível. É preciso atentar aqui, no entanto, ao momento de escritura da série: $\mathrm{Oz}$ é exemplar como obra de transição de um modelo do maravilhoso oitocentista para a fantasia moderna ainda nascente no século XX, sem, além disso, deixar de ser também uma utopia. O que confirma, de certa forma, o "parentesco" entre esses três modos narrativos. Nos termos de Tuerk (2007), Oz poderia ser interpretado da seguinte maneira:

Apesar de suas contradições, pode-se fazer algumas generalizações definitivas acerca do mundo dos livros de Baum. Primeiro, embora o autor alegue estar escrevendo contos de fadas "modernos" e "americanos", suas obras pegam muito emprestado dos contos de fadas e mitos europeus, e das tradições literárias europeias. $\mathrm{O}$ tipo exato de coisas que ele escreve não ter a intenção de usar - "incidentes desagradáveis", "corações partidos e pesadelos" e "incidentes horríveis de fazer gelar o sangue", encontradas nos contos europeus - abundam nos livros de Oz.

Segundo, a Oz de Baum é, do começo ao fim, uma terra feérica localizada no lugar nenhum dos contos de fadas. Mas não se trata de uma eutopia, ou um bom lugar, apesar de poder, de muitas maneiras, ser melhor do que os Estados Unidos da época de Baum e posterior. De muitos modos, entretanto, é pior. Problemas demais acontecem para ser o mundo ideal de Baum, e pesadelos demais estão presentes. (TUERK, 2007, p. 206, tradução de Carol Chiovatto ${ }^{24}$ ).

Logo, em Baum, tudo se mostra aparentemente possível, tudo parece um pouco aleatório, porque esse mundo é "um mundo fantástico", "encantado por fadas". Não obstante, esse viés é também um mundo secundário, um mundo complexo e existente no contexto narrativo, talvez o primeiro a ser tão detalhado e um dos primeiros - senão o primeiro, a trazer mapas não inspirados em locais de nossa própria realidade ou dentro do dito "mundo real". Em suma, trata-se de um mundo de protofantasia ou de uma fantasia avant la lettre, cujo sistema e cujas estruturas seguem ainda as funções narrativas do conto maravilhoso e das utopias. 


\section{Agradecimentos}

Este trabalho não seria possível sem a generosa contribuição de Carol Chiovatto, tradutora e pesquisadora dos livros de Baum no Brasil, que traduziu para o português as numerosas citações originalmente redigidas em inglês, bem como verteu o resumo deste trabalho. Agradeço também a Marcela Monteiro, professora e pesquisadora, pela gentileza e disponibilidade em revisar esse texto.

\section{Notes}

1. Uma versão inicial e bastante resumida deste trabalho foi apresentada em francês, sob o título "Le Monde d'Oz de L. Frank Baum: conte de fée moderne ou fantasy avant la lettre?", no colóquio Frontières et Limites de la Fantasy. Précurseurs, Apparentés, Compagnons de Route, realizado pela Université du Littoral Côte d'Opale (ULCO), na cidade de Boulogne-sur-Mer, França, nos dias 16 e 17 de maio de 2019. A programação completa está disponível em: https://modmed. hypotheses.org/942.

2. Tomo a liberdade de valer-me anacronicamente desse conceito contemporâneo para dar conta dessa história que deriva em linha indireta do segundo volume da série principal, na qual é contada uma aventura da personagem Woogle-Bug, chamada Zógol Besouro na tradução de Carol Chiovatto, bastante secundária na trama dos demais livros.

3. Os dois últimos volumes da série, $A$ Magia de $\mathrm{Oz}$ e Glinda de $\mathrm{O} z$, foram publicados postumamente, respectivamente, em 1919 e 1920.

4. Os livros de Thompson (dezenove no total), de Neill (responsável por três títulos) e de Snow (autor de dois livros), somam-se aos quatorze livros da série original de $\mathrm{Oz}$ de Baum e aos dois derradeiros volumes escritos respectivamente por Rachel R. Cosgrove (1922-1998) e por Eloise Jarvis McGraw (1915-2000) e Lauren Lynn McGraw (1944-), compondo o "Cânone de Oz", ou seja, os quarenta livros considerados oficiais pelos detentores dos direitos autorais do universo e dos personagens criados por Baum, lançados entre 1900 e 1963. Além desses, há inúmeros outros romances passados em $\mathrm{Oz}$, alguns com a devida autorização dos herdeiros, mas não inclusos no cânone, como Yankee in $O z$ (1972), também de Thompson, outros mais recentes, publicados após a série entrar em domínio público, e ainda alguns considerados não-oficiais, posto que não foram autorizados pelos herdeiros. Recentemente, novos livros foram considerados oficiais pela família de Baum, como é o caso da trilogia de Sherwood Smith publicada entre 2005 e 2014.

5. Não obstante tamanha notoriedade, os livros de $\mathrm{Oz}$ não são suficientemente conhecidos entre o público de língua portuguesa. Tanto no Brasil quanto em Portugal, a série completa permanece inédita (assim como em muitos outros países, como a França e a Bélgica). No Brasil, até muito recentemente, só os três primeiros volumes haviam sido traduzidos. O quarto volume foi publicado em português pela primeira vez apenas em 2015, com tradução de Carol Chiovatto. Os demais permanecem sem publicação nacional, embora a editora Vermelho Marinho, responsável por novas traduções dos três primeiros e pelo quarto volume antes inédito, tenha anunciado nas próprias publicações a intenção de lançar a série inteira. Consequentemente, como não existem traduções em português, não surpreende a quase inexistência de trabalhos críticos, acadêmicos ou não, dedicados a Baum e a sua obra. Até onde se pode consultar, não há nenhum livro em língua portuguesa dedicado à série, tampouco há teses de doutorado. Uma única dissertação de mestrado, bastante recente, foi localizada: A Representação do Feminino no Mundo de Oz, de L. Frank Baum, também de Chiovatto, defendida em 2017. Além de alguns prefácios nas várias edições do 
primeiro volume da série e de alguns poucos artigos inteiramente dedicados a $\mathrm{Oz}$ - a maioria assinada por Chiovatto - poucos trabalhos foram encontrados; em suma, o mundo de Baum permanece por explorar. A situação não é diferente em Portugal, ou nos países de língua espanhola ou francesa. Apenas em inglês, língua de redação não apenas da série de Baum, como da imensa maioria dos escritores que continuaram a expandir seu universo, há uma crítica verdadeiramente expressiva, tanto contemporânea ao autor, quanto recente. Essa situação é bastante curiosa dada a importância e a difusão da obra. Além disso, contrastase com a situação referente às obras de Lewis Carroll (1832-1898) e James M. Barrie (1860-1937), por exemplo, comparáveis uma vez que os três escritores publicavam obras em inglês dirigidas ao mesmo público em um espaço de tempo não muito extenso. A verdade é que, apesar de seu sucesso e de sua importância, notadamente para a cultura pop e transmidiática, a obra de Baum foi relegada a notas de rodapé em estudos de fantasia fora dos contextos norte-americanos. E, no entanto, seu mundo é apaixonante e complexo, sendo bastante relevante para a fantasia, enquanto modo narrativo, e, por isso, merece ser foco de novos estudos.

6. Cada volume da série se abre com um texto de Baum onde ele conta o que o motivou a escrevê-lo. Afora o primeiro, no qual delimitou seu desejo de produzir uma nova forma de narrativas infantis, ao mesmo tempo em diálogo com a tradição, tornando-as mais palatáveis e mais nacionais, as demais introduções versam, via de regra, sobre os pedidos dos "pequenos leitores" por mais histórias de $\mathrm{Oz}$ e pela reaparição desta ou daquela personagem, como no caso de Dorothy, que não tendo aparecido na segunda aventura, retorna como protagonista da terceira, ou do Mágico em si, personagem do volume inicial que volta no quarto tomo da série.

7. Há de se entender aqui o termo "fantástico" de acordo com a tipologia anglófona, isto é, como qualquer história em que se percebe uma disruptura do tecido da dita "realidade", na maioria das vezes por meio de uma intrusão ou presença de um elemento não realista (mágico, feérico, sobrenatural, extraterrestre etc.). Nesse sentido, a literatura fantástica, segundo a nomenclatura anglo-saxã, sobrepõe-se a outros termos "guarda-chuva", como o conceito de "insólito ficcional" difundido na América Latina e notadamente no Brasil, ou de "littératures de l'imaginaire", presente na tradição francófona, englobando diversas categorias literárias como o horror, o gótico, o maravilhoso, a fantasia etc. Diferencia-se, portanto, da acepção dada ao termo "fantástico" pelos países de língua francesa, portuguesa, italiana e espanhola, segundo os quais seria um modo narrativo bem específico utilizado para categorizar histórias onde há um confronto entre a realidade e o elemento sobrenatural, diferindo assim da fantasia, do maravilhoso e de outras categorias onde o sobrenatural é aceito como parte integrante do universo retratado. Não obstante isso, por influência da língua inglesa, não raro, no Brasil, utiliza-se a expressão "literatura fantástica" como conceito guarda-chuva. Por conta disso, convencionou-se a distinção didática: "fantástico lato sensu" (isto é, em seu sentido abrangente, como visto nos países anglo-saxões) e "fantástico stricto sensu" (ou seja, em seu sentido específico, conforme a tradição difundida nos países de línguas latinas).

8. No original: "One cannot overemphasize Baum's conscious development of the "modernized" fairy tale. There were, of course, earlier attempts at defining America as fairyland. Tales by Washington Irving and Nathaniel Hawthorne reflect this search for an indigenously American mythology. But Baum had no interest in preserving local legends as Irving did or in Hawthorne's disturbing metaphysics. Baum concerned himself with the immediate interests and desires of the child of his own time. He chose not, as Hawthorne did, to return to the Greco-Roman traditions to invent a mythology; he felt no need to imitate the Grimm's wonder tales, as Pyle did. He explained in his introduction to Baum's American Fairy Tales that his stories 
"bear the stamp of our times and depict the progressive fairies of today. He did not look back as did his predecessors. He was a Progressive, not a Romantic. He looked forward and sought new forms. Baum taught children, Edward Wagenknecht pointed out in Utopia Americana (Seatle: University of Washington Book Store, 1929), "to look for the element of wonder in the life around them, to realize that even smoke and machinery may be transformed into fairy lore if only we have sufficient energy and vision to penetrate to their significance and transform them to our use" (p. 29). Baum never succeeded in creating a purely "American" fairy tale. His witches and wizards, magic shoes and enchanted caps, came from Europe to inhabit the same universe as his scarecrows, patchwork girls, and magic dishpans" (HEARN, 2000, p. xlix).

9. No original: " $\mathrm{Oz}$ is a utopia, or no place, but it is not a eutopia, or good place. It is too full of dangers and discontent; otherwise, Oz books would probably be extremely boring. And $\mathrm{Oz}$ is not even Baum's idea of a eutopia, or good place, although in many ways it might be better than America of his day as he conceived of it. The basic difference between the world readers perceive and the world in the Land of $\mathrm{Oz}$ is, of course, that in $\mathrm{Oz}$ real magic works, so the real world cannot reproduce what happens there; it is the stuff of fantasy. With the science and technology available in Baum's day and even in our own, there is no way to replace all the parts of a human being with tin, and there is no way to make a man of straw come to life. Nor can people enable animals to think rationally, act on those rational thoughts, and communicate those thoughts in English to humankind. So $\mathrm{Oz}$ is indeed what J. R. $R$. Tolkien calls a "Secondary World", one quite distinct from what Tolkien call the "Primary World" in which real people live (36). Actually, since Baum's conception of $\mathrm{O} z$ changes from book to book, it might be more accurate to call $\mathrm{O} z$ a series of Secondary Worlds, distinct from the Primary World. And the appears to be no possible blurring of boundaries between $\mathrm{O} z$ and what Rogers calls "the everyday world". Although $\mathrm{Oz}$ can be reached from the real world as it exists within the $\mathrm{Oz}$ books, it cannot be reached from the real world in which real people live. Thus, it serves as sacred apace within the $\mathrm{Oz}$ books but as unattainable space within the real world" (TUERK, 2007, pp. 181-182).

10. No original: "Qu'est-ce que la fantasy? Dans une certaine perspective, bien entendu, c'est un jeu: un pur simulacre, sans aucune arrière-pensée. [...] Dans une autre perspective, la fantasy reste un jeu, mais [...] [c']est de lart, et non un divertissement spontané. Vue sous cet angle, elle s'apparente moins à la rêverie qu'aux rêves. Elle représente une autre approche de la réalité, une autre façon d'appréhender l'existence, une autre manière de l'affronter. La fantasy n'est pas anti-rationnelle, mais para-rationnelle; elle n'est pas réaliste, mas surréaliste, super-réaliste, une intensification de la réalité. [...] La fantasy s'approche de la poésie, du mysticisme et de la folie, beaucoup plus que ne le fait la fiction naturaliste. C'est une étendue véritablement sauvage, et ceux qui la parcourent ont intérêt à ne pas se croire hors de danger, et leurs guides, les écrivains de fantasy, $a ̀$ prendre leur rôle au sérieux" (LE GUIN, 2016, p. 90-91).

11. No original "L. Frank Baum Americanized the other-world fantasy. The portal fantasy was still quite new when Baum wrote The Wonderful Wizard of $\mathrm{Oz}$ (1900), the first in a long series. Previous fantasies in this mode from the English tended to be rather vague about modes of transport to the fantasy world, the location of that fantasy world, and its politics. Baum's $\mathrm{Oz}$ appers on maps (indeed, his are arguably the ancestors of all the maps which introduce so many modern fantasy trilogies). In later books there is a suggestion that $\mathrm{Oz}$ exists very close to Kansas. It can be reached in a house picked up by a whirlwind, or by sailing down a river. It has different countries, each with different polities, and there is a suggestion of an economic system" (MENDLESOHN; JAMES, 2009, p. 26).

12. Em sua dissertação de mestrado já citada, Chiovatto (2017) analisa em pormenor a inovação quanto à representação do feminino e da criança nos livros de Baum em contraste com outras histórias infantis como Alice no País das Maravilhas, 
Peter e Wendy, A Menina do Nariz Arrebitado e Chapeuzinho Vermelho, defendendo que Baum inova bastante em ambas as questões, mesmo à luz dos padrões contemporâneos.

13. No original: "tienen una existencia discontinua y autónoma respecto al mundo primario de los protagonistas” (SÁNCHEZ-ESCALONILLA, 2009, p. 92).

14. O livro A Rainha Zixi de Ix, por exemplo, se passa, é claro, no Reino de Ix, assim como o livro A vida e as aventuras do Papai Noel - e o conto dele derivado "O sequestro do Papai Noel" - se passam no Vale Feliz.

15. No original "loin d'imposer au lecteur une figure définitive qui briderait son imagination, "la carte, même fictive, suggère un au-delà de la fiction, qui serait le réel même, dans son étendue sans limites". C'est précisément parce quielle mime l'objectivité de la représentation cartographique "réaliste » ordinaire que la carte imaginaire élève l'univers fictif quelle décrit au rang de monde consistant et autonome - par où séclaire le paradoxal «besoin de cartes » de certains créateurs de récits" (GAREL-GRISLIN, 2019, p. 30).

16. A rigor, apenas o oceano é nomeado nos livros de Baum, o continente não recebe nome em suas obras ou mesmo nas obras de seus primeiros sucessores. O nome só viria a ser proposto por Robert R. Pattrick (1926-1960), autor de Unexplored Territory in $\mathrm{O} z$, publicado em 1963. Atualmente, é amplamente utilizado pelos comentadores das obras em torno do universo criado por Baum e nas ficções inspiradas por ele.

17. No original: "The most popular theory of the actual location of $\mathrm{O} z$ is that it must be somewhere in the South Pacific. In Baum's unproduced and unpublished play The Girl from $\mathrm{Oz}$ (1909), a character says that $\mathrm{Oz}$ is "some island far away in the Pacific." In the short story "Nelebel's Fairyland" (The Russ, June 1905), the heroine travels east from the Forest of Burzee, which is on the same continent as $\mathrm{Oz}$, to Coronado Bay, California. While on an ocean voyage to Australia in Ozma of $\mathrm{Oz}$ (1907), Dorothy gets marooned on the shores of the continent where $\mathrm{Oz}$ is located. Some people, like Oz Club member Sonia B. Brown in "Have We Discovered Oz?" (The Baum Bugle, Spring 1980), have argued unconvincingly that $\mathrm{Oz}$ is Australia" (HEARN, 2000, p. 30).

18. Conforme Hearn (2000) indica na edição comentada de O Maravilhoso Mágico de $\mathrm{O} z$, houve quem lesse $\mathrm{Oz}$ como uma narrativa de ficção científica, a partir da ideia de que $\mathrm{Oz}$ seria não um mundo secundário à parte, mas uma segunda dimensão, na qual nosso mundo evoluíra ou se transformara de forma distinta. Segundo essa leitura, essa outra dimensão seria acessível através da nossa por fissuras, o que explicaria os modos não usuais pelos quais Dorothy chegou a $\mathrm{Oz}$, um furacão no primeiro livro, uma tempestade em alto mar, no terceiro, um buraco causado por um terremoto no quarto e assim por diante. Essa teoria, no entanto, cai por terra, pois mesmo se a ideia de outra dimensão não é de todo descabida, a quantidade de elementos feéricos e/ou mágico-sobrenaturais impossibilita qualquer suposta explicação "racional" ou "científica", mesmo havendo alguma noção de ciência em Oz. A magia é algo intrínseco à estrutura do Mundo de $\mathrm{Oz}$ e se desenvolve em paralelo e complementarmente à tecnologia.

19. No original: "According to Raylyn Moore, Oz's being surrounded by deserts "suggests the undiscovered paradise which might have been an oasis at the core of the Great American Desert itself, if such a desert had existed on the scale imagined by mapmaker and early explorers" (96). According to Michael O. Riley, before the publication in 1914 of Tik-Tok of Oz, "the most general impression of the location of $\mathrm{O} z$ had been that it is in our world hidden away and difficult to get to, but a magical, marvellous, undiscovered part of America" (187). Since Dorothy first arrives in Oz by means of a tornado, such ideas seem plausible for the first $\mathrm{Oz}$ book. She arrives in $\mathrm{O} z$ the second time, however, as the result of a storm at sea when she is on the way to Australia, making it difficult to conceive of $\mathrm{O} z$ as part of America. Instead, Baum's $\mathrm{Oz}$ apparently exists in a kind of apace very different from that in which people really live and very 
different from that of America in Baum's day, a space in which magic works [...] Moore recognizes that $\mathrm{O} z$ also resembles "mythical islands for which explorers searched" ( $p$. 98), an idea that hints that $\mathrm{Oz}$ is to be thought of as being outside the physical world as people know it, a "mythical" rather than a real place. [...] Moore is right about Oz's resembling " $m y$ thical islands," then Baum's work probably descends in part at least from [Christopher] Cranch, [Jonathan] Swift, and [Daniel] Defoe, thus having American as well as European antecedents. At any rate, on Baum's "island" - surrounded not by water but by desert - magic works. As Trot says in The Magic of Oz, in Oz's "magic is so common" (145) (TUERK, 2007, p. 179-180).

20. Tal sociedade pregava a doutrina esotérica do teosofismo, em busca das ditas "verdades secretas" da vida e da morte, na tentativa de melhor compreender o mundo natural. De acordo com o anedotário, Baum entrou na sociedade graças ao auxílio de seu amigo, o escritor William P. Phelon, autor de Our Story of Atlantis (1903).

21. No original: "A likely inspiration for $\mathrm{Oz}$ was the legendary lost continent of Atlantis. Plato spoke of this mythical island at the mouth of the Mediterranean from which all Western philosophy, religion, and culture are said to originate, but which eventually was consumed by the sea. Ignatius Donnelly's Atlantis (1882) did much to revive interest in the myth in Baum's time; and the Ramayana Brotherhood, the branch of the Theosophical Society in Chicago to which the Baum belonged, followed what it called the old Altlantean [sic] Brotherhood of Hermes. Its leader Dr William P. Phelan claimed that he could contact Atlantis in a trance. Matilda Joslyn Gage, Baum's mother-in-law, believed she was a reincarnated Atlantean priest! $\mathrm{Oz}$, like Atlantis, is a land that Time has forgot, where witches and wizards still dwell and "civilization" has yet to invade. Under the name "Floyd Akers" in The Boy Fortune Hunters in Yucatan (1910), Baum played with the belief that survivors from Atlantis settled in Central America" (HEARN, 2000, p. 30).

22. Tomo a liberdade de fazer aqui uma nota pessoal para contar o contexto em que "descobri" este mapa. Em novembro de 2019, tive a oportunidade de visitar a exposição Tolkien, voyage en Terre $d u$ Milieu, que esteve em exibição na Biblioteca Nacional da França, em Paris, entre os dias 22 de outubro de 2019 e 16 de fevereiro de 2020. Tratava-se da primeira grande exposição concernente a esse autor, realizada em território francês, na qual foram expostos ao lado de manuscritos, ilustrações e objetos pessoais de Tolkien, vários artigos do acervo da própria instituição, tais como armaduras, tapeçarias, joias, quadros e mapas que, de alguma forma, se relacionassem direta ou indiretamente com o rico universo criado por Tolkien. Dentre esses artigos, encontrava-se justamente o mapa de Atlântida acima reproduzido, apresentado como um dos primeiros mapas de uma terra ficcional de que se tem notícia e que, portanto, dialogaria com a cartografia em torno da Terra Média, considerada uma das grandes inovações do escritor britânico. Contudo, ao ver essa ilustração de imediato percebi a identificação com o mapa de $\mathrm{Oz}$, o que motivou a pesquisa que aqui apresento. Pelo que pude averiguar, tal associação entre o mapa de 1775 e o mapa de Oz, publicado em 1900, nunca foi feita antes. Mais informações sobre a exposição estão disponíveis em seu site oficial: https://www.bnf.fr/fr/agenda/tolkien-voyage-en-terre-dumilieu.

23. No original: "Evidently, there are limitations to $\mathrm{Oz}$ magic, for even an imaginary world must play by a set of rules. "His world once invented," argued George MacDonald in "The Fantastic Imagination" in A Dish of Orts (1893), "the highest law that comes next into play is, that there shall be harmony between the laws by which the new world has begun to exist; and in the process of his creation, the inventor must hold by those laws. The moment he forgets one of them, he makes the story, by its own postulates, incredible. To be able to live a moment in an imagined world, we must see the laws of its existence obeyed. Those broken, we fall out of it." Not everything can be done in $\mathrm{Oz}$. When Dorothy in Glind of $\mathrm{Oz}$ (1920) proposes that everyone in $\mathrm{Oz}$ should be able to wish for whatever 
he or she desires, Ozma not only defends the Puritan work ethic, but also proves that she is a fairly good judge of human nature" (HEARN, 2000, p. 298).

24. No original: "In spite of his contradictions, there are some definite generalizations that one can make about the world of Baum's books. First, although Baum claim to be writing "modern" and "American" fairy tales, his works draw heavily on European fairy tales and myths and European literary traditions. The very kinds of things that he writes that he wants to dispense with - disagreeable incidents", "heartaches and nightmares," and "horrible and blood-curdling incidents" found in the European tales - abound in his $\mathrm{Oz}$ books. Second, Baum's $\mathrm{Oz}$ is, from first to last, a fairyland located in the no place of the fairy tale. This, it is indeed a utopia, a no place. But it is not a eutopia, a good place, although it may in many ways be better than the America of Baum's day and later. In many ways, however, it is worse. Too many problems occur for it to be Baum's ideal country, and too many nightmares are present" (TUERK, 2007, p. 206).

\section{Bibliografia}

BAUDOU, J. La Fantasy. Paris: PUF, 2005.

BAUM, L. F. A Maravilhosa Terra de Oz. Tradução de Carol Chiovatto. Rio de Janeiro: Vermelho Marinho, 2014a.

BAUM, L. F. Centennial Edition. The Annotated Wizard of Oz. Nova York: Norton \& Co., 2000.

BAUM, L. F. Dorothy e o Mágico em Oz. Tradução de Carol Chiovatto. Rio de Janeiro: Vermelho Marinho, 2015.

BAUM, L. F. O Maravilhoso Mágico de Oz. Tradução de Carol Chiovatto. Rio de Janeiro: Vermelho Marinho, 2014b.

BAUM, L. F. Ozma de Oz. Tradução de Carol Chiovatto. Rio de Janeiro: Vermelho Marinho, 2014c.

BERTRAND, J. M. Platão. In: RIOT-SARCEY, M.; BOUCHET, T.; PICON, A. (Orgs.). Dicionário das Utopias. Tradução de Carla Gamboa e Tiago Marques. Lisboa: Texto \& Grafia, 2009. p. 205-207.

BESSON, A. La Fantasy. Paris: Klincksieck, 2007.

CAVEE, C. Viagem. In: RIOT-SARCEY, M.; BOUCHET, T.; PICON, A. (Orgs.). Dicionário das Utopias. Tradução de Carla Gamboa e Tiago Marques. Lisboa; Texto \& Grafia, 2009. p. 258-259.

CHIOvatTO, A. C. A Representação do Feminino no Mundo de Oz, de L. Frank Baum. 2017. 185 f. Dissertação (Mestrado em Letras) - Universidade de São Paulo, São Paulo, 2017.

CHIOVATTO, A. C. Duas formas de representar o Feminino na literatura infantil: Narizinho, de Monteiro Lobato, e Dorothy, de L. Frank Baum. Revista Estudos Semióticos, São Paulo, v. 11, n. 2, p. 72-79, 2015. DOI: https://doi.org/10.11606/ issn.1980-4016.esse.2015.111037.

CUNHA, M. Z. da. Ozma de Oz: a experiência da aventura nas tramas do imaginário. In: BAUM, L. Frank. Ozma de Oz. Tradução de Carol Chiovatto. Rio de Janeiro: Vermelho Marinho, 2014. p. 204-215.

FONSTAD, K. W. O Atlas da Terra-Média. Tradução de Ronald Kyrsme. São Paulo: Martins Fontes, 2004.

GAREL-GRISLIN, J. Les coordonnées de la fiction: ce que la carte fait au récit. Revue de la Bibliothèque Nationale de France, Paris, n. 59, p. 22-30, 2019. DOI : https:// doi.org/10.3917/rbnf.059.0022. 
HEARN, M. P. Introduction to The Annotated Wizard of Oz. In: BAUM, L. Frank. Centennial Edition. The Annotated Wizard of Oz. Nova York: Norton \& Co., 2000. p. xiii-cii.

LE GUIN, U. K. Le langage de la nuit: essais sur la science-fiction et la fantasy. Tradução de Francis Guévremont. Paris: Aux Forges de Vulcain, 2016.

LEWIS, C. S. As Crônicas de Nárnia. Volume Único. Tradução de Paulo Mendes Campos e Silêde Steuernagel. São Paulo: Martins Fontes, 2005.

MANGUEL, A.; GUADALUPI, G. Dicionário de lugares imaginários. Tradução de Carlos Vaz Marques e Ana Falcão Bastos. Lisboa: Tinta da China, 2014.

MANGUEL, A. Prefácio à edição portuguesa. In: MANGUEL, A.; GUADALUPI, G. Dicionário de lugares imaginários. Tradução de Carlos Vaz Marques e Ana Falcão Bastos. Lisboa: Tinta da China, 2014. p. xi-xxxi.

MARQUES, Mirane Campos. Uma história que não tem fim: um estudo sobre a fantasia literária. 2015. 200 f. Tese (Doutorado em Letras) - Universidade Estadual Paulista Julio de Mesquita Filho, São José do Rio Petro, 2015.

MATANGRANO, B. A.; TAVARES, E. Fantástico Brasileiro: o insólito literário do romantismo ao fantasismo. Curitiba: Arte \& Letra, 2018.

MATANGRANO, B. A. Ordem vermelha: filhos da degradação, entre a alta fantasia e a distopia. Revista Estud. Lit. Bras. Contemp., Brasília, n. 56, p. 1-14, 2019. DOI: http://dx.doi.org/10.1590/2316-40185620.

MATANGRANO, B. A. Reinventando um gênero: o conto de fadas moderno de L. Frank Baum. In: BAUM, L. Frank. O Maravilhoso Mágico de Oz. Tradução de Carol Chiovatto. Rio de Janeiro: Vermelho Marinho, 2014. p. 195-203.

MENDLESOHN, F.; JAMES, E. A short history of fantasy. Londres: Middlesex University Press, 2009.

O MÁGICO de Oz. Victor Fleming. Estados Unidos: MGM Turner Entertainment Warner Bros., 1939.

PROPP, V. I. Morfologia do conto maravilhoso. Tradução de Jasna Paravich Sarhan. Rio de Janeiro: Forense Universitária, 2010.

TODOROV, T. Introdução à literatura fantástica. Tradução de Maria Clara C. Castello. São Paulo: Perspectiva, 2008.

RUAUD, A. F. Cartographie du merveilleux. Paris: Denoël, 2001.

SÁNCHEZ-ESCALONILLA, A. Fantasía de aventuras: claves creativas en novela y cine. Barcelona: Arial, 2009.

TOLKIEN, J. R. R. Sobre histórias de fadas. Tradução de Ronald Kyrmse. São Paulo: Conrad, 2006.

TUERK, R. Oz in perspective: Magic and Myth in the L. Frank Baum Books. Jefferson: McFarland \& Co, 2007. 